\title{
Boosting the antimicrobial action of vancomycin formulated in shellac nanoparticles of dual-surface functionality
}

Received 00th January 20xx, Accepted 00th January 20xxn

DOI: $10.1039 / x 0 x \times 00000 x$

rsc.li/materials-b

\author{
Saba S.M. Al-Obaidy, ${ }^{a, b}$ Ahmed F. Halbus, ${ }^{a, b}$ Gillian M. Greenway and Vesselin N. Paunov ${ }^{a *}$
}

We report a strong amplification of the antimicrobial action of vancomycin (VCM) encapsulated in shellac nanoparticles (NPs) with dual surface functionalisation. These shellac nanocarriers for VCM were produced in two steps: (i) a pH drop from aqueous ammonium shellac solution containing Poloxamer 407 (P407) as a steric stabilising polymer in solution of vancomycin hydrochloride, and (ii) subsequent doping with the insoluble cationic surfactant octadecylthrimethylammonium bromide (ODTAB) though a solvent change to yield cationic surface functionality. We evaluated the encapsulation efficiency of VCM and its release profiles from these nanocarriers. This study explored the antibiotic action of these VCM nanocarriers at the various stages of their preparation which helped us to evaluate how they could be made to work efficiently, to adapt their design and demonstrate the role of the nanocarrier dual functionalisation on its antibiotic action and delivery. The antibiotic effect of VCM loaded in such versatile functionalised shellac nanocarriers was tested on three different proxy microorganisms, $C$. reinhardtii, S. cerevisiae and $E$. coli. We also compared the antibiotic effect of free VCM with non-coated VCM-loaded nanocarriers at the same overall concentrations. The ODTAB coating of the shellac NPs strongly enhanced the antibiotic action of the encapsulated VCM across all tested microorganisms. The enhanced VCM action is explained with the increased electrostatic adhesion between the ODTAB-coated VCM-loaded shellac NPs and the negatively charged surface of the microbial cell walls which allows local delivery of VCM with a high concentration directly on the cell membrane. This nanocarrier-mediated boost of the antibiotic action may potentially breathe new life into old antibiotics and help to fight off antibiotic resistance by making them more effective.

\section{Introduction}

Vancomycin (VCM) is a glycopeptide antibiotic produced from Streptomyces orientalis) $)^{1,2}$ with high activity against Grampositive bacteria. It acts by inhibiting the synthesis of the second stage of the cell wall, through strong binding to peptides that contain D-alanyl-D-alanine at the end of free carboxyl groups. ${ }^{3}$ Studies have revealed that VCM also changes the cell membrane permeability. ${ }^{4}$ This antibiotic is usually prescribed to treat infections caused by methicillin-resistant Staphylococcus aureus MRSA or is given to patients allergic to penicillin or cephalosporin. ${ }^{5}$ It is used largely in intensive care units to treat sepsis and hospital infections, as well as for empyema, endocarditis, pneumonia cases, soft tissue abscesses and osteomyelitis. ${ }^{6-8}$ Due to its side effects such as phlebitis, hypotension, nephrotoxicity, tachycardia, ototoxicity, chills, hypersensibility reactions, fever and exanthema make this drug is the last resort. ${ }^{6,8-10}$ It has been used to reduce the infections

\footnotetext{
a. Department of Chemistry and Biochemistry, University of Hull, Hull, HU67RX, UK. b. Department of Chemistry, College of Science, University of Babylon, Hilla, Iraq. *Corresponding author: Tel: +44 1482 465660; E-mail: v.n.paunov@hull.ac.uk † Electronic supplementary information (ESI) available. See DOI: 10.1039/
}

obtained after posterior cervical fusion surgery ${ }^{11}$ and can decrease the occurrence of postsurgical wound infections. ${ }^{12-14}$ A number of reports of resistance to VCM has turned researchers toward new VCM formulations using nanocarrier delivery systems such as nanoparticles and liposomes, which offer greater intracellular penetration and the possibility for effective intracellular antibacterial action over extended time periods. ${ }^{15}$ Nanocarrier systems have been widely developed in the pharmaceutical industry due to their ability to control the release of drugs for efficient delivery. ${ }^{16}$ Recently, formulation of biodegradable nanocarriers has attracted much attention following concerns about their post-use fate. ${ }^{17,18}$ Biodegradable NPs from renewable natural materials such as lignin, cellulose and shellac have a wide range of industrial and pharmaceutical applications. Frangville et al. ${ }^{19}$ developed biodegradable lignin nanoparticles which showed no measurable toxicity against proxy organisms such as yeast and microalgae. Recently, these were applied in a delivery system based on $\mathrm{Ag}^{+}$-loaded lignin NPs which were coated with cationic polyelectrolyte. ${ }^{20,21} \mathrm{Al}-$ Awady et al.22 demonstrated that the antimicrobial action of polyelectrolyte-coated NPs alternates with the particle surface charge and developed surface-functionalised nanogels for encapsulation of antimicrobial 23,24 

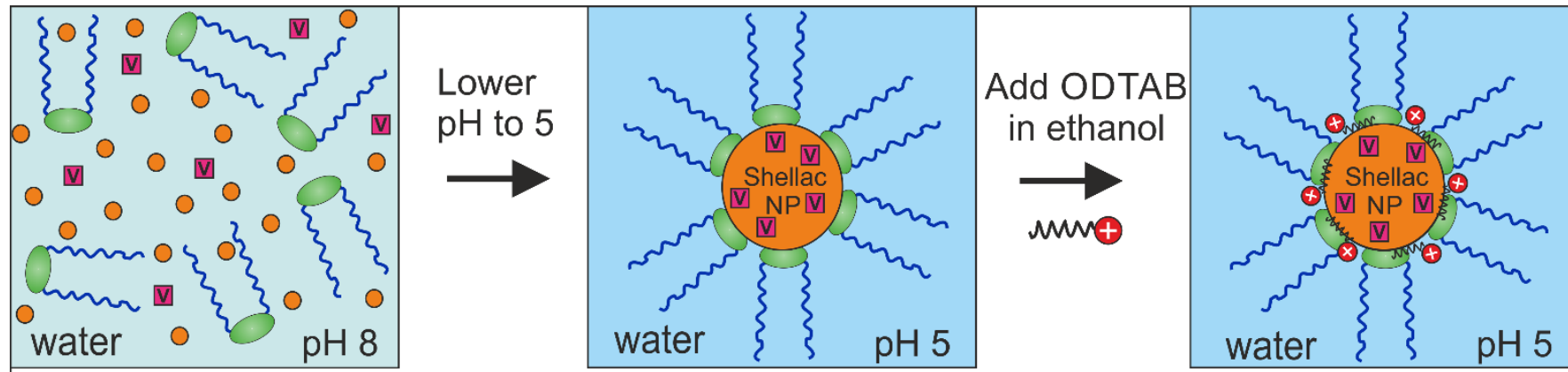

\section{A Legend: \\ P4O7 V Vancomycin hydrochloride \\ shellac \\ unt ODTAB}

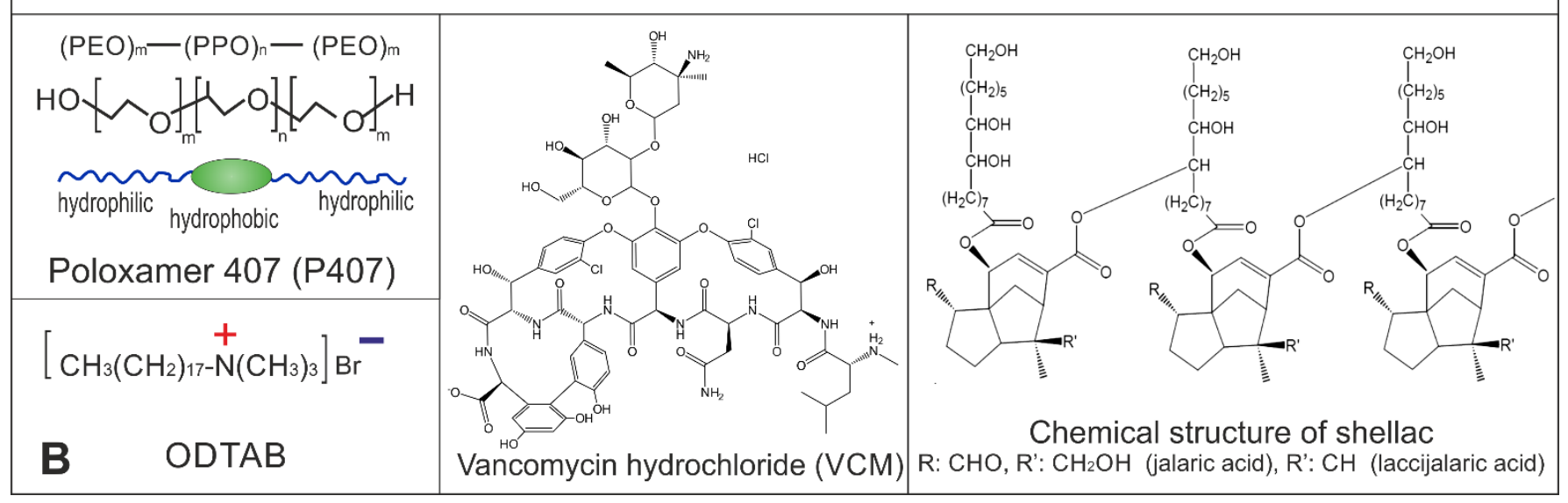

Figure 1. (A) Schematics of the two step process for the preparation of dual functionalised shellac nanocarriers for vancomycin (VCM). The VCM-loaded shellac NPs are sterically stabilised with Poloxamer 407 (P407) and have cationic surface functionality achieved by subsequent doping with the cationic surfactant octadecyltrimethyl ammonium bromide (ODTAB). (B) Structural formulas of the constituting materials for the preparationon of vancomycin-shellac nanocarriers: P407, ODTAB, VCM and the main components of shellac.

VCM has been loaded within N-trimethyl chitosan (TMC) particles for drug delivery applications which had a significant antibacterial action against $S$. aureus with sustained delivery of VCM to bone infections. ${ }^{25}$ Zakeri-Milani et al. enhanced the VCM intestinal permeation by loading VCM into (PLGA) poly(lactide-co-glycolide) nanoparticles. ${ }^{26}$ VCM loaded in solid lipid nanoparticles adjuvanted with linoleic acid, showed better antibacterial activity than free VCM in aqueous solution towards both resistant and susceptible bacteria. ${ }^{27} \mathrm{VCM}$ was also successfully encapsulated into amino-polysiloxane matrixes through a one-step room temperature sol-gel method. ${ }^{28}$ Esmaeili et al. ${ }^{29}$ prepared $\mathrm{VCM}$-loaded $\mathrm{MnFe}_{2} \mathrm{O}_{4}$ nanoparticles by using a co-precipitation methodand showed that their antibacterial activity can be improved by coating them with chitosan. Table 1 summarizes some of the characteristics of recently reported VCM loaded nanocarriers. In most cases these VCM carriers have relatively large particle size and negative surface charge which can potentially repel them from with the microbial cell membrane. In addition, most studies report VCM cytotoxicity prevalently against Gram-positive rather than Gram-negative bacteria.

In this study, we aimed to develop a stable VCM-nanocarrier with high efficiency against Gram-negative bacteria, such as $E$. coli, as well as yeast and algal cells. As a nanocarrier material, we choose shellac, which is the refined product of the natural material Lac secreted by the small parasitic insect Kerria lacca on different host trees in South Eastern Asia. It has numerous applications in agriculture, food products and enteric coatings for tablets, $^{30}$ lacquers, ${ }^{31,32}$ dental baseplates,,33,34 dental varnishes ${ }^{35,36}$ coating and matrix material, $31,37,38$ additive in foods and cosmetic products, encapsulating agent in pharmaceuticals, ${ }^{39-41}$ as well as a moisture barrier coating. ${ }^{42,43}$ Shellac is a complex mixture of polar and non-polar components consisting of polyhydroxy acids, lactones and anhydrides, ${ }^{44-46}$ it has a pKa of 6.9 to 7.5 and it is acid resistant, 47 being practically insoluble in acidic to neutral aqueous medium $(\mathrm{pH}<7) .39,48,49$ Colloidal shellac dispersion have been used for coatings, precipitated from alcoholic shellac solution in water. ${ }^{50}$ Krause and Muller $^{51}$ reported preparation of an aqueous shellac dispersion using a high pressure homogenisation technique, although their particle size was rather large $(\sim 5 \mu \mathrm{m})$. Colloidal shellac with particle size 150-300 nm was formulated by Patel et $a .^{52}$ for silibinin encapsulation by using an anti-solvent method and xanthan gum as stabilizer. Kraisit et al. ${ }^{53}$ used chitosan as stabilizer to prepare shellac suspensions with size range 100-300 $\mathrm{nm}$ for encapsulation of bovine serum albumin. Here, e developed shellac NPs that could be loaded with VCM, and stabilised by using Poloxamer 407 (P407) copolymer to 
sterically stabilize them. P407 is a non-ionic co-polymer made up of poly (ethylene oxide)(PEO)-poly (propylene oxide)(PPO) poly (ethylene oxide)(PEO) (see Figure 1B), which is widely used in pharmaceutical formulations as a surfactant, solubilizing agent, emulsifying and dispersing agent. ${ }^{54,55}$ We further apply a secondary functionalization with a very small amounts of a nonsoluble cationic surfactant, ODTAB to inverse the particle surface charge from negative to positive.

Figure $1 \mathrm{~A}$ outlines the steps of the VCM encapsulation into the shellac nanocarriers and their surface functionalisation. The retention of the VCM in the cores is based on hydrophobic and electrostatic interactions within the shellac matrix of the nanocarrier particles. This steric stabilisation also plays a synergistic effect with the cationic surface functionalisation of the VCM nanocarrier and can be potentially used in topical/ dermal formulation. ${ }^{55}$ The positive surface charge of the ODTAB-coated nanocarrier allows it to adhere electrostatically to the microbial cell walls and to deliver locally a high concentration of VCM which boost its antibiotic action on various types of microbial cells. The loaded VCM within shellac NPs allows the antibiotic to be released slowly which mean it can potentially be used in wound dressings over longer periods of time. The choice of ODTAB as a secondary surface treatment allows direct deposition on the shellac NPs surface while the already formed sterically stabilizing P407 layer in the first step remains intact. This strategy proved very successful, as the carrier maintained its steric stability while being surface chargereversed by the secondary coating with ODTAB.

Note that the synthesis of our shellac nanocarrier is a "one pot" preparation and allows the cationic antimicrobial or antibiotic (e.g. VCM) to be easily encapsulated in the produced nanocarrier which amplify its action. Its mechanism of action is to deliver high local concentration of antibiotic/antimicrobial directly on the microbial cell membrane by electrostatic adhesion and to potentially increase its permeability due to the presence of both ODTAB and Poloxamer on the nanocarrier surface. Similar amplification approaches have been recently designed based on cationically functionalized polyacrylic acid nanogels loaded with antimicrobials ${ }^{23,82}$ as well as inorganic antimicrobial particles like CuONPs with grafted phenyl boronic acid surface groups which covalently bind to sugar groups on the bacteria, thus concentrating the CuONPs on the microbial cell membrane and enhancing its antimicrobial effect. ${ }^{83}$ This approach is different to the action of the cationic antimicrobial peptides, which act as bacterial membrane disruptors which are similar to cationic polyelectrolytes with the advantage of being more biocompatible. Recently, however Zhang et al. ${ }^{84}$ combined a cationic peptite-fulerene conjugate which showed good results in antibacterial photodynamic therapy (PDT) with improved efficiency as compared to non-treated fullerene. Similarly, the antibacterial effect of the reactive oxygen species produced in the PDT are amplified by the cationic peptide which "dock" their source on the bacteria surface. Alternative strategy has been proposed by Zou et al. ${ }^{85}$ for photothermal nanodots based on self-assembly of peptide-porphyrin conjugates for antitumor therapies which may also find antibacterial applications. ${ }^{83}$ Borovicka et al. ${ }^{86-88}$ combined silica-imprints of microbial cells with incorporated gold nanoparticles to produce photothermal colloid antibodies for selective laser ablation of targeted microorganisms. Interesting approach based on imprinting of $\beta$-lactamase on hydrogel was adopted by Li et al. ${ }^{89}$ to treat antibiotic resistant bacteria. The imprinted sites trap $\beta$ lactamase excreted by drug-resistant bacteria, thus making bacteria sensitive to antibiotics. Dong et al. ${ }^{90}$ developed a NIRsensitive nanoplatform for synergistic eradication of antibioticresistant bacteria based biofilms both in vitro and in vivo. The integration of nanotherapeutics (NO-donor) and antimicrobial compounds (quaternary ammonium chitosan) into one system could significantly enhance biofilm dispersal as well as prevent the recurrence and reduce side effects.

We studied the antibacterial, anti-fungal and anti-algal action of the nanoparticles compared with free VCM on three proxy microorganisms, C. reinhardtii, S. cerevisiae and E. coli, respectively. We also studied the VCM release kinetics from the carrier and the boost of its antimicrobial action before and after surface functionalising of the shellac NPs with ODTAB. We show that this strategy can strongly amplify the antimicrobial action of both VCM compared to solutions with an equivalent concentration of free VCM or the non-loaded nanocarrier.

\section{Materials and Methods}

\section{Materials}

Shellac was used in a soluble form as the ammonium salt at $\mathrm{pH}$ $>7$. The ammonium shellac solution was a gift from (Stroever Schellackbremen, Germany) and is commercially available as SSB Aqua Gold ${ }^{\mathrm{TM}}$ (solid content 25\%). Poloxamer 407 (purified), vancomycin hydrochloride (98\%), and 3', 6'-diacetyle fluorescein (FDA), were all obtained from Sigma-Aldrich UK. Octadecyltrimethyl ammonium bromide (ODTAB) was supplied by Fluka Chemika, UK. Deionised water purified by reverse osmosis and ion exchange from a Milli-Q water system (Millipore, UK) was used in all our studies. Its surface tension was $71.9 \mathrm{~m} \mathrm{Nm}^{-1}$ at $25^{\circ} \mathrm{C}$, with measured resistivity less than 18 $\mathrm{M} \Omega \mathrm{cm}^{-1}$. The BacTiter-Glo ${ }^{\mathrm{TM}}$ microbial cell viability assay was purchased from Promega, UK. Chlamydomonas reinhardtii (cc124 strain) was kindly provided by Flickinger group from North Carolina University, USA. This microalgae culture was grown in Tris-Acetate-Phosphate (TAP) culture medium and incubated at a temperature of $30^{\circ} \mathrm{C}$. The $\mathrm{C}$. reinhardtii culture media consisted of TAP salts $\left(\mathrm{NH}_{4} \mathrm{Cl} ; \mathrm{MgSO}_{4} .7 \mathrm{H}_{2} \mathrm{O}\right.$ and $\left.\mathrm{CaCl}_{2} \cdot 2 \mathrm{H}_{2} \mathrm{O}\right)$, phosphate buffer solution (PBS) and Hutner's trace elements solution (EDTA disodium salt, $\mathrm{ZnSO}_{4} .7 \mathrm{H}_{2} \mathrm{O}, \mathrm{H}_{3} \mathrm{BO}_{3}, \mathrm{MnCl}_{2} .4 \mathrm{H}_{2} \mathrm{O}$, $\mathrm{CoCl}_{2} .6 \mathrm{H}_{2} \mathrm{O}, \mathrm{CuSO}_{4} .5 \mathrm{H}_{2} \mathrm{O}, \mathrm{FeSO}_{4} .7 \mathrm{H}_{2} \mathrm{O},\left(\mathrm{NH}_{4}\right)_{6} \mathrm{Mo}_{7} \mathrm{O}_{24} \cdot 4 \mathrm{H}_{2} \mathrm{O}$, all purchased from Sigma-Aldrich, UK. The microalgae batch was grown in the TAP media at $\mathrm{pH} 7$ while being illuminated for 72 hours with a white luminescent lamp with a light intensity of 60

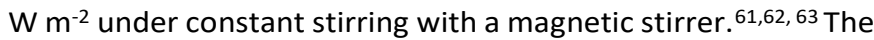
stock cultures of $C$. Reinhardtii were with typical concentration $4 \times 10^{5}$ cells $\mathrm{mL}^{-1}$ determined by cell counter (Nexcelom Cellometer Auto $\mathrm{X} 4$ ) and the E. coli bacterial culture stock was with approximately $5 \times 10^{7}$ cells $\mathrm{mL}^{-1}$. Saccharomyces cerevisiae (Baker's yeast), was purchased from Sigma-Aldrich. It was 
cultured by hydrating $10 \mathrm{mg}$ of lyophilized yeast cells in $10 \mathrm{~mL}$ of Milli-Q water. Then $1 \mathrm{~mL}$ of this hydrated suspension was added to $100 \mathrm{~mL}$ of autoclaved YPD culture media ${ }^{64}$ consisting of peptone (Sigma Aldrich, UK), D-glucose, (Fisher Scientific, UK), and yeast extract, (Oxoid Itd, UK.), then incubated at $30^{\circ} \mathrm{C}$ for 24-48 hours. Escherichia coli, sourced from Thermofisher (Invitrogen MAX Efficiency ${ }^{\mathrm{TM}}$ DH10B ${ }^{\mathrm{TM}}$ ) was used for our antibacterial tests. The cells were cultured in autoclaved LuriaBertani medium (LB medium) ${ }^{65}$ prepared by dissolving $0.5 \mathrm{~g}$ yeast extract, $0.5 \mathrm{~g}$ sodium chloride (Sigma Aldrich), and $1 \mathrm{~g}$ tryptone (Oxido ltd), in $100 \mathrm{~mL}$ water. Fluorescein diacetate (FDA, 98\%) for cell viability assays was supplied from Sigma Aldrich, UK.

\section{Preparation and functionalization of VCM-loaded shellac NP}

Shellac NPs were prepared by mixing $0.25 \mathrm{w} / \mathrm{v} \%$ of ammonium shellac salt and VCM solution at $\mathrm{pH} 8$ with different concentrations of P407 and VCM. $100 \mathrm{~mL}$ of this solution was prepared, followed by lowering the solution $\mathrm{pH}$ to 5 by adding drop-wise $0.01 \mathrm{M} \mathrm{HCl}$ with a syringe pump at a rate of $220 \mathrm{~mL} / \mathrm{h}$ while agitating with a magnetic stirrer. The concentration of VCM was varied in a mixture of shellac and P407 with a constant ratio of $0.25 \mathrm{wt} \%: 0.2 \mathrm{wt} \%$, respectively. In order to promote their adhesion to the negatively charged microbial cell walls, the shellac NPs surface charge was altered from negative (P407stabilised shellac NPs loaded with VCM) to positive by an additional surface doping with the cationic surfactant ODTAB. Typically, 0.07 wt.\% of VCM was loaded in 0.25 wt.\% shellac NPs which were further coated with ODTAB delivered to the shellac NP suspension by drop-wise addition from $3 \%$ ODTAB in ethanol.

\section{Shellac NPs size, zeta-potential and morphology characterisation}

The particle size and zeta-potential of the shellac NPs with and without VCM were measured by dynamic light scattering (DLS) using a Zeta sizer Nano ZL (Malvern Instrument Ltd, UK). All measurements were carried out in triplicate. Morphological examination of the nanoparticles was performed by transmission electron microscopy (TEM) (Joel 2010, Japan), a few drops of the sample were placed on carbon-coated copper grids and negatively stained with $1 \%$ aqueous uranyl acetate. Once air dried, the sample was imaged with a Gatan Ultrascan 4000 digital camera attached to Jeol 2010 TEM at 200kV.

\section{Fourier transform infrared (FTIR) and UV-vis spectroscopy study}

FTIR spectroscopy (Thermo Fisher Scientific Nicolet 380 FT-IR, Hemel Hempstead, UK) was used to characterise the shellac NPs and VCM-loaded shellac NPs. This technique was also used to confirm the adsorption of P407 on shellac NPs surface and the intercalation between the VCM and the molecules of the shellac matrix. In order to confirm the loading percentage of VCM within shellac NPs a UV-Vis spectrophotometry technique was used. A sample of VCM-loaded shellac NPs was dissolved in alkaline solution $(\mathrm{pH} 8)$ and the spectrum was recorded between 220-700 $\mathrm{nm}$ using the spectrophotometer (model Bio Lambda 10, USA). Spectra were also recorded at the same range for free VCM and shellac NP coated with P407. The stability of VCM encapsulated in shellac nanoparticles was confirmed by using FTIR spectra and UV-vis spectroscopy at temperature $25^{\circ} \mathrm{C}$ and $37^{\circ} \mathrm{C}$. The VCM-loaded shellac NPs was heated at $37^{\circ} \mathrm{C}$ for 2 hours. The VCM-loaded shellac NPs was cooled down to room temperature.

\section{Encapsulation efficiency and VCM loading contents in shellac NPs}

The encapsulation efficiency and the drug loaded content was indirectly calculated by measuring the absorptivity of the nonencapsulated drugs. The non-encapsulated VCM solution was filtered using a $20 \mathrm{~nm}$ syringe filter and the absorbance of this filtered VCM solution was measured at $422 \mathrm{~nm}$ using the UV-Vis spectrophotometer. A calibration curve of VCM was made by measuring the absorbance of a series of standard VCM solutions. The VCM loading contents and encapsulation efficiency were calculated as shown below 66

$$
\begin{aligned}
& \text { Encapsulation Efficiency }(\%)=\frac{[\text { Total VCM }- \text { Unencapsulated VCM }]}{[\text { Total VCM }]} \times 100 \\
& \text { Drug Loading Content }(\%)= \\
& =\frac{[\text { Total VCM }- \text { Unencapsulated VCM }] \times 100}{[(\text { Total VCM }<- \text { Unencapsulated VCM })+\text { shellac }+ \text { Poloxamer amount }]}
\end{aligned}
$$

\section{In vitro VCM release kinetics from shellac NPs}

The dialysis method was used to determine the in vitro VCM release profile from the shellac NPs. $50 \mathrm{~mL}$ of the sample containing of VCM-loaded shellac NPs were dialyzed (see Figure $\mathrm{S} 3, \mathrm{ESI})$. A dialysis bag of $12-14 \mathrm{~K}$ MWCO with a pore diameter $2.5 \mathrm{~nm}$ was immersed in a $500 \mathrm{~mL}$ buffer phosphate solutions (for $\mathrm{pH} 5.5$ and 7.4). The bag was stirred gently with an orbital shaker at $37^{\circ} \mathrm{C}$ temperature and $100 \mathrm{rpm}$. At specific time intervals, $2 \mathrm{~mL}$ of the dialysis solution was taken and analysed by measuring the UV-vis absorbance from 200-700 nm. Measurements were taken in triplicates at 15, 30, 60, 120, 180, $240,300,360$ and $1440 \mathrm{~min}$. The cumulative percentage of released VCM was calculated using the equation ${ }^{67}$

$$
\% \text { In Vitro VCM Release }=\frac{M_{\text {released }}}{M_{\text {total }}} \times 100,
$$

where $M_{\text {released }}$ is the amount of drug released from the shellac NPs at time $t$ and $M_{\text {total }}$ is the amount of drug loaded.

\section{Antimicrobial activity of the non-coated VCM-loaded shellac NPs}

Stock suspensions of VCM-loaded shellac NPs against different concentrations of the non-coated and ODTAB-coated VCMloaded shellac NPs were incubated with fixed aliquots of the microbial cells cultures for different incubation time. The cells were removed from their growth media and transferred in MilliQ water. Shellac NPs without VCM (as a negative control) and free VCM aqueous solution (positive control) was incubated as with equivalent cell samples for the same durations. The viability of $C$. reinhardtii and yeast was measured using a cell counter after incubating $1 \mathrm{~mL}$ of the treated cells (washed from the shellac NPs), with $10 \mu \mathrm{L}$ of $0.1 \%$ FDA in acetone for $10 \mathrm{~min}$ and washing with deionised water by centrifugation. 
Table 1. Summary of the reported nanocarriers for Vancomycin (VCM) within their characteristics.

\begin{tabular}{|c|c|c|c|c|c|}
\hline Nanocarrier used to encapsulate VCM & Particle size $/ \mathrm{nm}$ & Zeta potential /mV & E.E. $/ \%$ & Drug content / \% & Reference \\
\hline $\mathrm{N}$-trimethyl chitosan (TMC) & 220 & $15 \pm 1$ & $74 \pm 2$ & $5.8 \pm 0.17$ & 56 \\
\hline Poly vinyl alcohol (PVA) & $430 \pm 32$ & $26 \pm 10$ & $89 \pm 2$ & $30 \pm 1$ & 57 \\
\hline Liposome formulation F2 & 78 & - & 79 & 98 & 58 \\
\hline Poly vinyl alcohol (PVA) F2 & $461 \pm 33$ & $-7 \pm 6$ & $67 \pm 2$ & $34 \pm 2$ & 59 \\
\hline Polyacrylic acid sodium (PAA) & $230 \pm 48$ & $-30 \pm 5$ & $75 \pm 1$ & $58 \pm 1$ & 60 \\
\hline
\end{tabular}

The $E$. coli viability was measured after incubating the cells with the VCM-loaded NPs. $100 \mu \mathrm{L}$ of the treated E. coli suspension was washed and mixed with $100 \mu \mathrm{L}$ of BacTiter-Glo ${ }^{\mathrm{TM}}$ cell viability reagent in white opaque 96 -well microplate and shaken for 5 minutes. The bioluminescence intensity was then measured (BMG LABTECH instrument, FLUOstar Omega, Germany).

\section{Protocol for SEM imaging of the treated cell samples}

The cells were washed with Milli-Q water 3 times to remove the residual NPs by centrifugation at $3000 \mathrm{rpm}$ for 3 minutes. The cell sample was deposited on dry Aclar ${ }^{\mathrm{TM}}$ sheets or poly-lysine coated glass coverslips, fixed with $2.5 \mathrm{w} / \mathrm{v} \%$ glutaraldehyde for 2 hours, followed by washing with cacodylate buffer.

Table 2: Vancomycin loading content at $\mathrm{pH} 6$ encapsulated with Composition 1 (0.25 wt\% shellac: 0.2 wt\% P407) and Composition 2 (0.5wt\% shellac:0.4wt\% P407)

\begin{tabular}{ccc}
\hline $\begin{array}{c}\text { VCM loaded in shellac } \\
\text { NPs } / \mathrm{mol} \mathrm{mL}^{-1} \times 10^{-7}\end{array}$ & $\begin{array}{c}\text { Drug loading (\%) } \\
\text { using Composition 1 }\end{array}$ & $\begin{array}{c}\text { Drug loading (\%) } \\
\text { using Composition 2 }\end{array}$ \\
\hline 6.9 & 2.33 & 0.9 \\
20.7 & 6.8 & 3.5 \\
34.5 & 10.6 & 5.8 \\
48.3 & 13.6 & 7.6 \\
\hline
\end{tabular}

The cells were post fixed for 1 hour in $1 \mathrm{wt} . \%$ osmium tetroxide, washed with a cacodylate buffer, then rinsed with serial ethanol-water solutions starting from $50 \%$ ethanol moving up to absolute ethanol, then dried using a critical point dryer. Finally, the samples were coated with carbon $(\sim 10 \mathrm{~nm})$ in an evaporator and imaged using scanning electron microscope SEM (ZEISS EVO 60 EP-SEM, Germany).

Cytotoxicity assay of VCM-loaded shellac NPs coated with ODTAB on $\mathrm{HaCaT}$ cells

We tested the biocompatibility of our nanocarrier on HaCaT cel line culture (immortalized human keratinocytes) which was kindly provided by the Skin Research Group at St James University Hospital at Leeds. The cells were cultured in highglucose DMEM media supplemented with $10 \%$ Fetal Bovine Serum (FBS, Labtech, UK) and $1 \%$ antibiotics (Penicillin Streptomycin, Lonza, UK) and placed in an incubator $\left(37^{\circ} \mathrm{C}, 5 \%\right.$ $\mathrm{CO}_{2}$ ). After reaching $70 \%$ confluence, $\mathrm{HaCaT}$ cells were carefully washed with PBS for $10 \mathrm{~s}$ then incubated with $0.25 \%$ TrypsinEDTA (1X, Lonza, UK) to detach the cells from their support after $5 \mathrm{~min}$. Its action was neutralized by adding complete DMEM medium before a centrifugation at $400 \times \mathrm{g}$ for $4 \mathrm{~min}$. An $25 \mathrm{~mL}$ aliquot of the HaCaT cells culture ( 75000 cells $\mathrm{mL}^{-1}$ ) were washed three times from the culture media via centrifuged, and re-dispersed with $25 \mathrm{~mL}$ PBS. Then, $2.5 \mathrm{~mL}$ aliquots of this $\mathrm{HaCaT}$ cells suspension were incubated with a series of $2.5 \mathrm{~mL}$ aliquots of aqueous dispersions of VCM-loaded shellac NPs coated with ODTAB at different concentrations. Likewise, a control sample of the HaCaT cells was treated at the similar conditions. After that, $1 \mathrm{~mL}$ of the HaCaT suspension was taken from each addressed sample with ODTA-coated VCM-loaded shellac NPs, washed with PBS to remove the excess of VCMloaded shellac NPs coated with ODTAB via centrifuged at $400 \times \mathrm{g}$ for $4 \mathrm{~min}$. The HaCaT cells were re-suspended in $1 \mathrm{~mL}$ of PBS, then two drops of $1 \mathrm{mM}$ FDA solution in acetone was added to each sample and mixed together for 15 min followed by triple washing with PBS by centrifugation at $400 \mathrm{~g}$ for 4 min. Finally, a microplate reader was utilized to assess the HaCaT cell viability.

\section{Results and Discussion}

\section{Preparation and characterisation of VCM-loaded shellac NPs}

Figures $2 \mathrm{~A}$ and $2 \mathrm{~B}$ and show the particle size distribution and the zeta potential of shellac NPs formulated by mixing $0.25 \mathrm{wt} . \%$ of shellac with 0.2 wt.\% P407 at pH 5. This yielded shellac NPs of average size of $65 \mathrm{~nm}$ and negative zeta-potential of $-22 \mathrm{mV}$. Figure $2 \mathrm{C}$ shows the dependence of the shellac particle size and zeta potential on the $\mathrm{pH}$ of the solution. One can see that the particle size is insensitive to $\mathrm{pH}$ as the shellac particles are sterically stabilised, while the zeta-potential is negative due to the dissociation of the $\mathrm{COOH}$ groups of the shellac constituents. Note that ODTAB was not used here to coat the shellac NPs.

Figure 2D shows the size and the zeta potential of the shellac NPs at different concentrations of P407. The size remains fairly constant above 0.2 wt.\% P407 while the zeta-potential decreases slightly due to the offsetting of the surface charge by the PEO chains of the attached P407 layers. Figure 2E shows that the size of the shellac NPs increased when VCM loading concentration increased. The results indicate that shellac NPs can be formed with a VCM loading concentration of up to 0.07 wt. \% at 0.25 wt.\% shellac. Further increase in the VCM concentration resulted in a continuous increase in the particle size, starting from $\sim 80 \mathrm{~nm}$ at $0.01 \mathrm{wt} . \%$ VCM to $\sim 96 \mathrm{~nm}$ at $0.07 w t . \%$ VCM. At higher VCM loading concentrations aggregation occurs. 

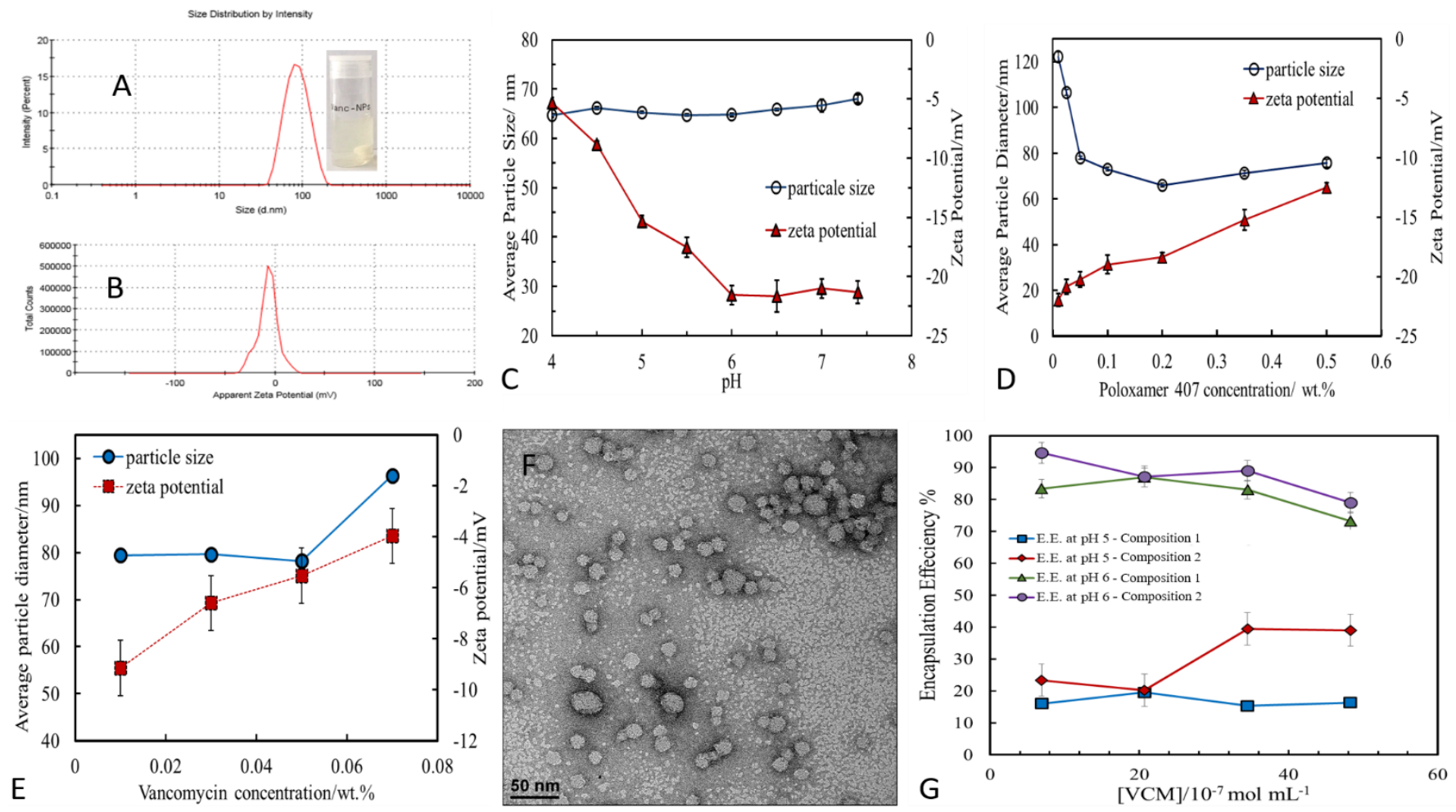

Figure 2. (A) Particle size and (B) zeta-potential distribution of shellac nanoparticles was obtained by mixing a ratio of $0.25: 0.2 \mathrm{wt}$.\% of ammonium shellac: $\mathrm{P} 407 \mathrm{from} \mathrm{pH} 8$ to $\mathrm{pH} 5$ in deionized water. (C) The shellac NPs average diameter and zeta-potential as a function of the pH of the media. (D) The average diameter and zeta-potential of the non-coated non-loaded shellac NPs as a function of the P407 concentration in the initial formulation. (E) The shellac NPs average diameter and zeta-potential as a function of the VCM concentration. (F) TEM of ODTAB-coated VCM-loaded shellac NPs; (G) The encapsulation efficiency percent of different concentrations of VCM-loaded shellac NPs at pH 5 and pH 6 and different shellac and P407 overall concentrations. Compositions 1 and 2 are specified in Table 2.

The zeta-potential of the VCM-loaded shellac NPs decreased slightly with an increase in the VCM loading concentration which is probably due to the electrostatic attraction between the dissociated carboxylic groups of the shellac constituents and the VCM cations. TEM images revealed some of the morphological characteristic of VCM-loaded shellac NPs, as seen in Figure 2F. The images show that the shape of the shellac NPs is spherical with a size less than $100 \mathrm{~nm}$ for uncoated shellac NPs, which also agrees with the DSL measurements at $\mathrm{pH} 5$ (see Figure 2A). We also examined the long term stability of the shellac carriers sterically stabilised by $\mathrm{P} 407$ over the course of 90 days by DLS measurements. Figure S1 (ESI) shows that both particle size and zeta potential remained stable over this period. Figure S2B (ESI) shows the TEM image of the shellac NPs suspension sample after drying, and reveals the spherical shape of the NPs with a an average size of $33 \pm 11 \mathrm{~nm}$ as can be seen in Figure S2A. This supports the result obtained by using the DLS measurements that the shellac particles are consistently smaller than $100 \mathrm{~nm}$. The effect of VCM concentration on the encapsulation efficiency was examined indirectly by measuring the amount of non-encapsulated VCM (Figure S3A, ESI) using VCM standard calibration curve (Figure S3B, ESI). VCM was encapsulated with shellac NPs by following the procedure described in the previous section. Figure $2 \mathrm{G}$ shows that the encapsulation efficiency of VCM at $\mathrm{pH} 5$ was low. In order to enhance it we varied the $\mathrm{pH}$ and the overall amounts of shellac and P407. This allowed us to increase the VCM encapsulation efficiency from $19 \%$ at $\mathrm{pH} 5$ to $88 \%$ at $\mathrm{pH} 6$ (Composition 1, see Table 2). Doubling the concentrations of shellac and P407 (0.5 wt.\%:0.4 wt.\%) (Composition 2, Table 2) increased the VCM encapsulation efficiency further, while the VCM loading contents within shellac NPs dropped from $13.6 \%$ to $7.6 \%$ at 48.3 $x 10^{-7} \mathrm{~mol} \mathrm{~mL}^{-1} \mathrm{VCM}$. In all experiments throughout VCM was encapsulated at $\mathrm{pH} 6$ by using the same Composition 1 of shellac and P407 (0.25 wt.\%:0.2 wt.\%) as it was deemed more efficient.

\section{FTIR and UV-Vis studies}

The FTIR spectra of VCM, shellac NPs, and VCM-loaded shellac NPs, are represented in Figure 3A. The FTIR of free VCM (purple line) revealed a phenolic $\mathrm{OH}$ stretching band at $3261 \mathrm{~cm}^{-1}$, stretching aromatic $\mathrm{C}=\mathrm{C}$ associated with amide $\mathrm{I}$ at $1644 \mathrm{~cm}^{-1}$, $\mathrm{C}=\mathrm{O}$ stretching association with secondary amide shows peak at $1488 \mathrm{~cm}^{-1}$, C-O phenolic, C-N-H amide II, and Ar-O-Ar showed peaks at wavenumbers at $1395 \mathrm{~cm}^{-1}, 1585 \mathrm{~cm}^{-1}$ and $1059 \mathrm{~cm}^{-1}$ respectively. ${ }^{58,68}$ Although the shellac NPs and the VCM-shellac NPs spectrum (blue line) have a high degree of similarity as VCM has similar functional groups $(\mathrm{O}-\mathrm{H}, \mathrm{C}=\mathrm{C}$, and $\mathrm{C}-\mathrm{H})$, the small shoulders that appear at $1648 \mathrm{~cm}^{-1}$ and $1060 \mathrm{~cm}^{-1}$ for aromatic $\mathrm{C}=\mathrm{O}$ amide and $\mathrm{Ar}-\mathrm{O}-\mathrm{Ar}$ stretching, respectively, belong to $\mathrm{VCM}$ which indicates its successful encapsulation in shellac NPs. 

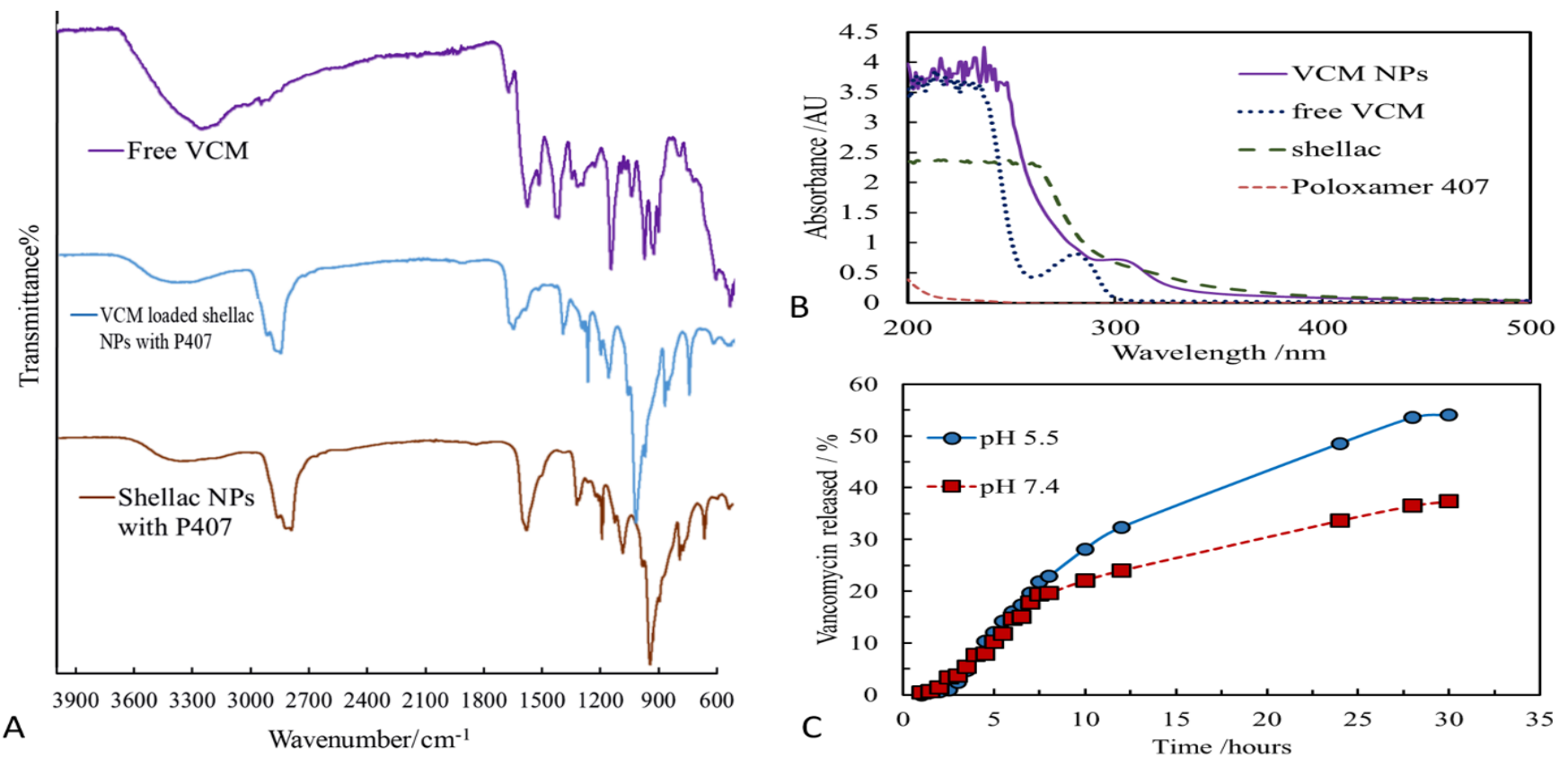

Figure 3. (A) Fourier Transform Infra-Red (FTIR) spectra of free VCM, VCM loaded in shellac NPs with P407, and shellac NP coated with P407 without VCMs; (B) UV-Vis absorption spectrum of VCM, free shellac, non-coated VCM-loaded shellac NPs and P407; (C) The percentage of in vitro VCM release as a function of time at different pH. The error bars are within the symbol size.

Some of the $\mathrm{P} 407$ peaks overlap with the shellac peaks although there is no chemical reaction between shellac and P407. This interaction is probably due to the adsorption of the hydrophobic part of $\mathrm{P} 407$ on shellac surface, and $\mathrm{O}-\mathrm{H}$ stretching band still exist at $3392 \mathrm{~cm}^{-1}$, while the carbonyl stretching vibration $(\mathrm{C}=\mathrm{O})$ and $\mathrm{C}-\mathrm{O}$ stretching bands appears at $1711 \mathrm{~cm}^{-1}$ and $1241 \mathrm{~cm}^{-1}$ respectively. The VCM encapsulation within the shellac NPs was also confirmed by using UV-vis spectroscopy. A sample of VCM loaded shellac NPs was dissolved in weakly basic medium then the absorbance was measured at a range of 200$500 \mathrm{~nm}$, as well as for free shellac, free VCM and P407. Figure $3 B$ shows the free VCM spectrum (blue line) with a characteristic peak at $280 \mathrm{~nm}$ with random peaks between 200$236 \mathrm{~nm}$. The shellac spectrum also displayed random peaks started from $264 \mathrm{~nm}$ to $200 \mathrm{~nm}$, whereas P407 does not show a specific peak in the UV-vis spectrum. The purple line, which represents VCM-shellac NPs, reveals a peak at $304 \mathrm{~nm}$, which belongs to VCM but is slightly shifted due to the interaction with shellac and random peaks start from $247 \mathrm{~nm}$ to $200 \mathrm{~nm}$ which belong for both shellac and VCM-shellac NPs. This confirms the VCM encapsulation within the shellac.

\section{VCM encapsulation efficiency and release kinetics}

Figure 3 C shows VCM release profile from shellac NPs at pH 5.5 and 7.4 for over 30 hours. This shows that the released percentage \% of VCM-loaded shellac NPs at pH 5.5 is higher than at $\mathrm{pH}$ 7.4. For the the first few hours, the release of VCM was slow and similar for both $\mathrm{pHs}$, but after 24 hours the release increased at $\mathrm{pH} 5.5$ and reached to $48.5 \%$ of total VCM amount while at $\mathrm{pH} 7.4$ it was only $24 \%$. The high release of $\mathrm{VCM}$ at $\mathrm{pH}$ 5.5 can be attributed to the weaker protonation of shellac carboxylic groups in acidic media which led to weaker electrostatic interactions with the VCM cations released in the media. Compared to other studies, ${ }^{68}$ these shellac NPs loaded VCM showed a sustained release over longer periods of time.

We also tested the stability of the VCM-loaded shellac nanocarrier system at two different temperatures, $25^{\circ} \mathrm{C}$ and 37 ${ }^{\circ} \mathrm{C}$ for up to 6 hours of incubation. Figure S9 shows the UV-Vis spectra of the VCM-loaded nanocarrier after incubation at $37^{\circ} \mathrm{C}$ which show no significant change.

\section{Cationic surface functionalisation of shellac NPs}

Figure 4 shows that size and zeta-potential distribution of the ODTAB-coated VCM loaded shellac NPs. One sees that the surface charge can been reversed by adding different amounts of ODTAB in ethanol solution after the preparation of the shellac NPs (at $\mathrm{pH} 5.5$ ). Figure $4 \mathrm{C}$ shows that the zeta potential of VCM-loaded shellac NPs decreased with the increase of the concentration of added ODTAB. 0.07 wt.\% ODTAB was considered to be the optimal amount to coat $0.05 \mathrm{wt} . \% \mathrm{VCM}$ loaded shellac NPs with zeta potential of $+10 \mathrm{mV}$ and $\sim 98 \mathrm{~nm}$ mean diameter. Morphological characterisation of these particles using scanning electron microscopy revealed that they have a spherical shape and an average size consistent with that obtained from the DLS measurements (see Figure 4D).

\section{The toxicity effect of the non-loaded shellac NPs}

To check whether the loading of VCM within the shellac nanoparticles could enhance the antibacterial activity of VCM, a blank experiment was carried out first where the cytotoxic effect of the empty (non-loaded) shellac nanocarrier, was studied on three different types of cells: microalgae, yeast and bacteria. 

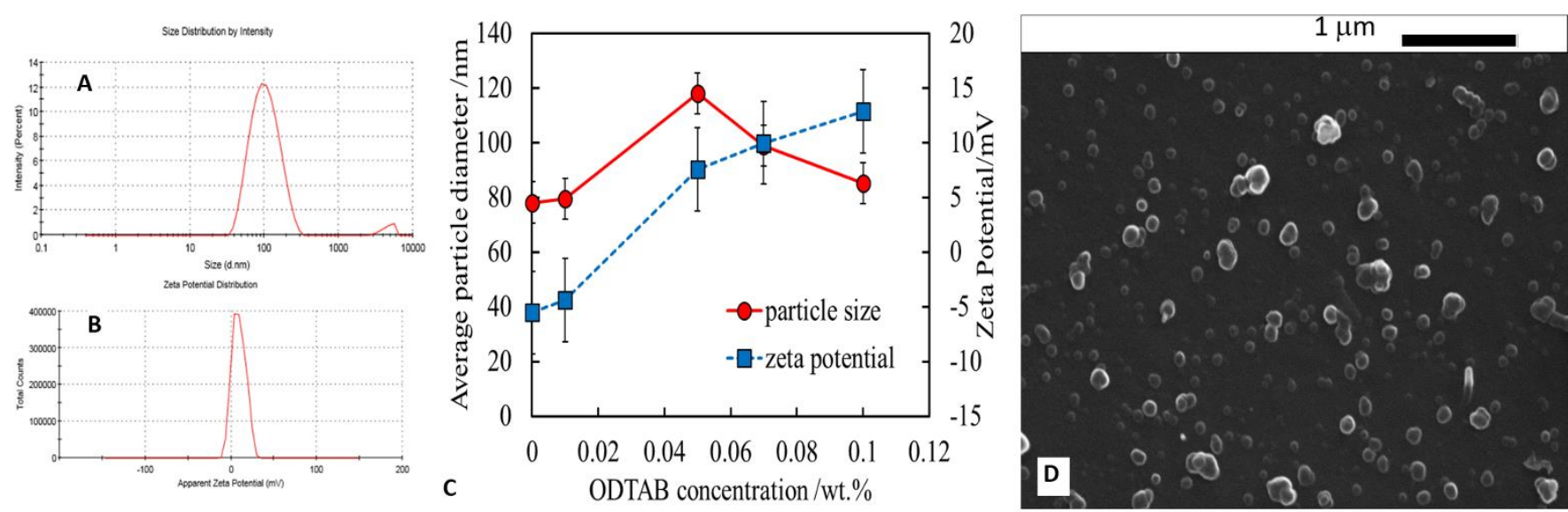

Figure 4. (A) Particle size and (B) zeta-potential distribution of shellac nanoparticles of $0.05 \mathrm{wt}$. \% VCM loaded Shellac NPs after coating with 0.07 wt. \% of ODTAB at pH 5.5. (C) The effect of coating of $0.05 \mathrm{wt}$.\% VCM-loaded shellac NPs with different concentrations of ODTAB on the size and zeta potential at pH 5 . (D) Scanning electron microscopy image of 0.05 wt. \% of VCM NPs after coating with 0.07 wt. \% of ODTAB.

The live/dead assay for shellac NPs was determined by incubation of the cells with shellac NPs suspensions of different shellac concentrations produced by serial dilutions of more concentrated stock. The cells were removed from the culture media to avoid any interaction between shellac NPs and media components. Figure 5 shows the cytotoxic effect of shellac NPs without VCM on C. reinhardtii, S. cerevisiae and $E$. coli, respectively. As it can be seen from Figure $4 A$, there is a small cytotoxic effect of shellac NPs on the algal cells at relatively high concentration due to the P407, which was used as a stabilizer. It has been previously reported that P407 might create a adsorption layer on the microbial cell surface, ${ }^{69-71}$ so the combination between P407 and the shellac NPs may play a synergistic antimicrobial role within this nanocarrier design. The shellac NPs, however, showed no pronounced effect when incubated with yeast and E.coli for 6 hours, as demonstrated in Figures $5 \mathrm{~B}$ and $5 \mathrm{C}$. One possible explanation for the lack of effect on yeast is that its cells have much a thicker cell wall which mitigates the effect of P407 at these concentrations. For all cell types studied, lower concentration of the shellac NPs are benign over the duration of the experiment ( 4 hours). At this concentration of nanocarriers we were able to evaluate the effect of the VCM - see below.

\section{Antimicrobial activity of VCM-loaded shellac NPs}

We compared the antimicrobial activity of free VCM and VCMloaded shellac NPs (non-coated) on the same microbial cultures, C. reinhardtii, S. cerevisiae and E. coli in order to determine whether the loading of VCM within shellac NPs could enhance its antimicrobial activity. The purpose of encapsulating VCM within shellac NPs was to increase its antibiotic action. It was anticipated that the increased surface area of the nanocarrier, would result in the need for less VCM, thus reducing the potential side effects of the VCM and making it more bioavailable in medical formulations increasing its efficacy. ${ }^{72-76}$
However, our experiments showed that the VCM encapsulation in the shellac nanocarriers generally lowered its efficiency.

Fig. S4 shows the cell viability of the $C$. reinhardtii as a function of the concentration of free VCM. The antialgal activities of free VCM and VCM-loaded shellac NPs were studied on microalgae at different incubation times and at room temperature to examine their effects on $C$. reinhardtii as presented in Figures S4A and S4B (ESI). The algae cells were incubated with solutions of various concentrations of free VCM up to $0.1 \mathrm{wt} . \%$. At the highest VCM concentration, the algal cell viability steadily declined to about $50 \%$ after 6 hours of incubation. Figure S4B shows that VCM showed lower activity after loading it within shellac NPs compared with free VCM at the same concentration and incubation time. After 4 hours incubation of the cells with different concentrations of VCM-loaded shellac NPs, their viability did decrease slightly by about $10 \%$ at $0.05 \mathrm{wt}$. $\%$ of VCM. After 6 hours, the cell viability dropped by $15-20 \%$. The reason why the antimicrobial activity decreased after loading VCM within shellac NPs is because of the repulsion between negatively charged shellac NPs and the negatively charged algal cell membrane which repels the nanocarrier and does not allow VCM to be released in its immediate vicinity. This impairs the effect of the nanocarrier. The SEM images of $C$. reinhardtii cells in Figure S4E and S4F show that the free VCM caused damage to the cell membranes whereby cells have shrunk and appear wrinkled in comparison with control sample as shown in Figure S4C and S4D. In comparison, the effect of the VCM-loaded shellac NPs on the cell membrane of algae seems less pronounced as in Figures S4G and S4H (see ESI). The antifungal activity of free VCM and VCM loaded shellac NPs were studied on $S$. cerevisiae cells at different concentrations at $\mathrm{pH} 5.5$ using the FDA live/dead assay. Figure S5A and S5B show the effect of free VCM and VCM loaded NPs on S. cerevisiae at a range of incubation times. 

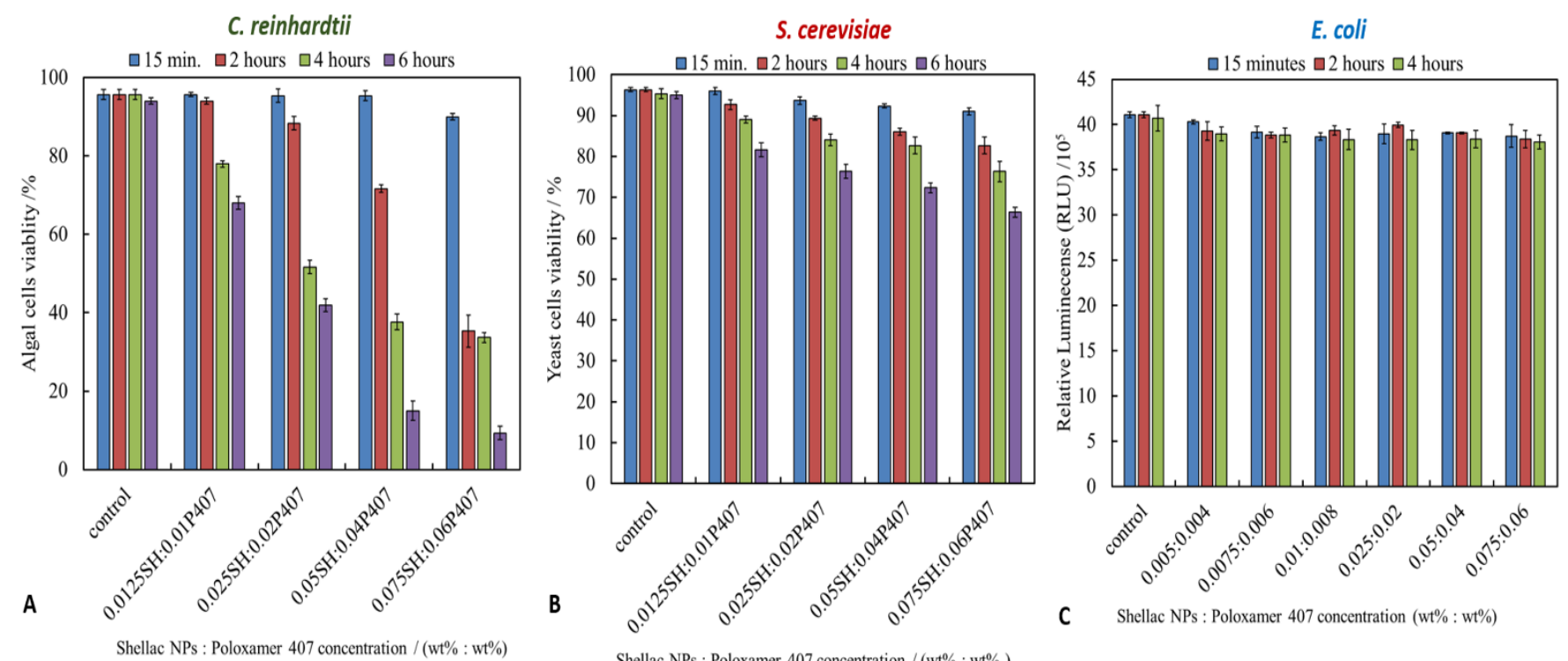

Shellac NPs : Poloxamer 407 concentration / (wt $\%$ : wt $\%)$

Figure 5. The effect of the P407 stabilised non-loaded shellac NPs on the viability of (A) C. reinhardtii, (B) S. cerevisiae and (C) E. coli cells incubated with different concentrations of shellac NPs (made from fixed ratio of $0.25 \mathrm{wt}$.\% ammonium shellac and $0.2 \mathrm{wt} . \% \mathrm{P} 407$ ) at different incubation times. The ratios on the $\mathrm{x}$-axis show the actual concentrations of both shellac and P407. No VCM was used in these experiments. Here the shellac NP were stabilised by P407 but not coated with ODTAB.

Figure S5A shows that free VCM had weak effect on the yeast cells although some effect was seen at high concentrations of free VCM. At $0.1,0.15$ and 0.25 wt.\% of VCM the cell viability decreased from $97 \%$ for the control (no VCM) to $70 \%, 62 \%$, and $58 \%$ respectively after 4 hours of incubation. After 6 hours of exposure to VCM, the cell viability declined slightly from $98 \%$ at control to be $62 \%, 54 \%$ and $45 \%$ at $(0.1,0.15$, and 0.25$)$ wt. $\%$, respectively. At shorter incubation times the VCM effect was negligible. Loading the VCM within shellac NPs was seen to reduce its anti-yeast effect as shown in Figure S5B. The VCMloaded shellac NPs showed very low activity toward the yeast cells due to the repulsion between the NPs and cell wall. The SEM images of yeast cells after being incubated for 4 hours with 0.01 wt.\% of free VCM (Figure S5E and S5F) and VCM loaded shellac NPs (Figure S5G and S5H), show that they both did not have a visible effect on the yeast cells membranes in comparison with the control (Figure S5C and S5D) at these concentrations. This indicates that the non-coated VCM-loaded shellac NPs are ineffective against yeast.The antibacterial activity of free VCM and VCM-loaded shellac NPs was compared after incubating E.coli with different concentrations of free VCM and measuring the cell viability by by using BacTiter-Glo ${ }^{\mathrm{TM}}$ luciferase assay. Figure S6A shows the effect of free VCM at different exposure times. Note that even at longer times the VCM showed medium antibacterial activity, possibly as it is more effective as Gram-positive antibacterial agent and due to its large size that can hardly penetrates the cell walls of Gramnegative bacteria. 77,78

We found that the antibacterial effect of the VCM-loaded in shellac NPs was even smaller than that of free VCM as shown in Figure S6B. After 4 hours of exposure, the cell viability declined by about $20 \%$ at $(0.0005,0.001$, and 0.005$)$ wt.\% of total VCM concentration and reduced by about $50 \%$ at 0.025 wt.\% of VCM after 6 hours. Figures S6E and S6F (ESI) show the SEM images of E.coli cells incubated with 0.01 wt.\% of free VCM and VCM loaded shellac NPs (Figures S6G and S6H) in comparison with control (Figures S6C and S6D). Although one can see some very low degree of deposition of NPs on the E.coli cell membranes in Figure $\mathrm{S} 6 \mathrm{G}$ and their wrinkling in Figure $\mathrm{S} 6 \mathrm{H}$ the effect does not seem to correlate directly with the cell viability (Figure S6B), which is higher than the one for free VCM (Figure S6A). As with algae and yeast, one can conclude that the encapsulation of the VCM in the shellac nanocarrier does not give immediate advantages over the use of free VCM at the same total concentration. We attribute this to the lack of adhesion of the non-coated nanocarriers to the microbial cell membranes.

\section{Cationic surface functionalised shellac nanocarriers}

In order to reverse the negative surface charge of the shellac NPs, we coated them with ODTAB which was added from ethanol solution. ODTAB is a cationic surfactant but it is practically insoluble in water at room temperature. Although cationic surfactants have moderate toxicity, after coating on the nanocarrier surface with ODTAB, it has very limited antibacterial effect on the $E$. coli cell viability (Figure S7). Figure $S 8$ shows the SEM images of the three types of microbial cells incubated with non-loaded ODTAB-coated shellac NPs. One can see that there is a significant accumulation of the ODTAB-coated nanocarrier particles on the surface of the cell walls for $C$. reinhardtii (Figures S8A and S8B) and E.coli (Figures S8E and S8F). Yeast cells (Figures S8C and S8D) clearly show changes on their cell wall morphology, but no ODTAB-coated nanocarrier particles have remained attached after the SEM sample preparation. 

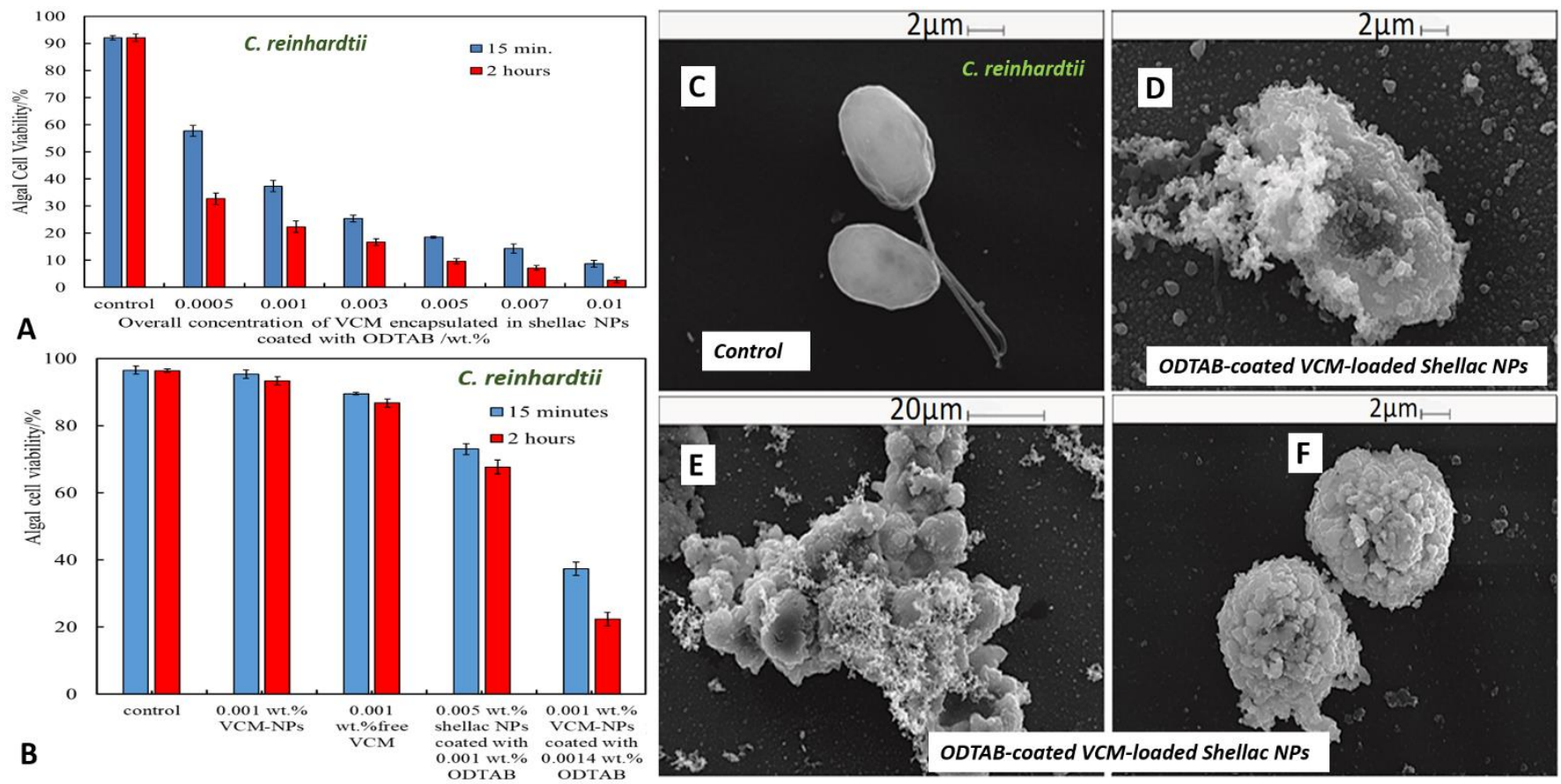

B

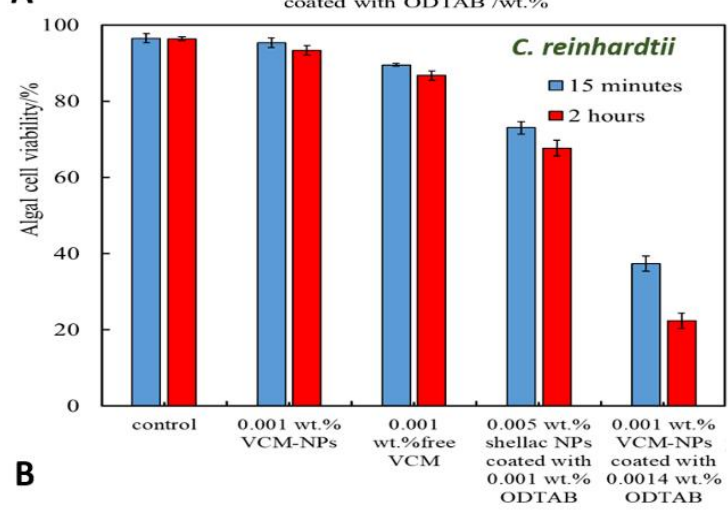

Figure 6. (A) The viability of $C$. reinhardtii upon incubation at pH 5.5 with aqueous solutions of different concentrations of VCM encapsulated in ODTAB-coated shellac NPs. The solutions were prepared from $0.05 \mathrm{wt} . \%$ VCM-loaded shellac NPs coated with 0.07 wt.\% ODTAB stock solution. (B) The $C$. reinhardtii viability upon incubation with 0.001 wt. $\%$ encapsulated VCM in shellac NPs, 0.001 wt.\% free VCM, 0.005 wt.\% shellac NPs coated with 0.001 wt.\% ODTAB, 0.001 wt.\% VCM-loaded in shellac NPs coated with 0.0014 wt.\% ODTAB, and $0.001 \mathrm{wt} . \%$ pure ODTAB at pH 5.5 and at room temperature. (C)-(F) SEM images of $C$. reinhardtii whereby (C) represent the control sample, (D)-(F) sample incubated with 0.001 wt.\% VCM-loaded shellac NPs coated with 0.0014 wt. \% ODTAB after 2 hours incubation at room temperature.

One may draw comparison with Figures S5E and S5F where the shellac nanocarrier is not charged positively. One possible explanation for the different result for yeast is that the cell wall is not sufficiently charged for strong electrostatic adhesion to retain the particles during the SEM sample preparation.

\section{Antimicrobial effect of ODTAB-coated VCM-loaded shellac NPs}

The anti-algal activity of ODTAB-coated VCM-loaded shellac NPs was studied by incubating $C$. reinhardtii at different overall concentrations of VCM (Figure 6A).After only $15 \mathrm{~min}$ of incubation, the cell viability of microalgae decreased sharply from $92 \%$ for the control sample to $(25,18.5,14$, and 8.5$) \%$ at $(0.003,0.005,0.007$, and 0.01) wt.\% VCM-loaded shellac NPs coated with ODTAB. After 2 hours the cell viability of $C$. reinhardtii continued to decrease to $(9.5,7$, and 2.5$) \%$ at $(0.005$, 0.007 , and 0.01 ) wt.\%, VCM-loaded in shellac NPs coated with ODTAB. The effect is much stronger than the anti-algal effect of the same concentration of VCM, i.e. after coating with ODTAB, the VCM-loaded nanocarrier increased its anti-algal action. Figure $6 \mathrm{~B}$ compares the anti-algal activities of $0.001 \mathrm{wt} . \% \mathrm{VCM}$ loaded in shellac NPs, $0.001 \mathrm{wt} . \%$ free VCM, $0.005 \mathrm{wt} . \%$ shellac NPs coated with 0.001 wt.\% ODTAB without VCM and 0.001 wt.\% VCM-loaded shellac NPs coated with 0.0014 wt.\% ODTAB There is a clear change in the anti-algal action of VCM after coating it with ODTAB. Scanning electron microscopy images of algal cell after incubated with $0.01 \mathrm{wt} . \%$ VCM-loaded shellac NPs coated with 0.014 wt.\% ODTAB for 2 hours can be seen in
Figure 6D-6F. The SEM images show that the VCM-loaded NPs accumulate around the cell wall in abundance; this attraction allows the NPs to release VCM directly on the cell membrane which effectively kill them as shown in Figure 6B. The anti-yeast effect of the VCM-loaded shellac NPs coated with ODTAB was examined by incubating culture media free yeast cells at different overall concentrations of VCM at different incubation time. Figure 7A shows the yeast cell viability upon incubation with different concentrations of VCM loaded shellac NPs coated with ODTAB for 15 minutes. The cell viability steeply decreased from $94 \%$ for the control to $38 \%, 32 \%, 3.3 \%$ and $2.8 \%$ at $(0.0005$, $0.001,0.003$ and 0.005$)$ wt.\% of VCM-loaded in shellac NPs coated with $(0.0007,0.0014,0.0042$, and 0.007$)$ wt.\% ODTAB, respectively. These suspensions were produced by gradual dilution of more concentrated stock. Figure 7B compares the anti-yeast actions of 0.005 wt.\% VCM-loaded in shellac NPs, 0.005 wt.\% free VCM, 0.025 wt.\% shellac NPs coated with 0.007 wt.\% ODTAB (no VCM) and 0.005 wt.\% VCM-loaded in shellac NPs coated with 0.007 wt.\% ODTAB. One can see that using ODTAB to change the surface charge of the NPs from negative to positive significantly increased the anti-yeast action of the VCM in the nanocarrier. Figure 7 shows SEM images of yeast cells incubated with $0.01 \mathrm{wt} . \%$ VCM-loaded in shellac NPs coated with 0.014 wt.\%. ODTAB. The coated shellac NPs also showed antimicrobial effect due to the positive surface charge which synergistically increase the effect of the VCM. 

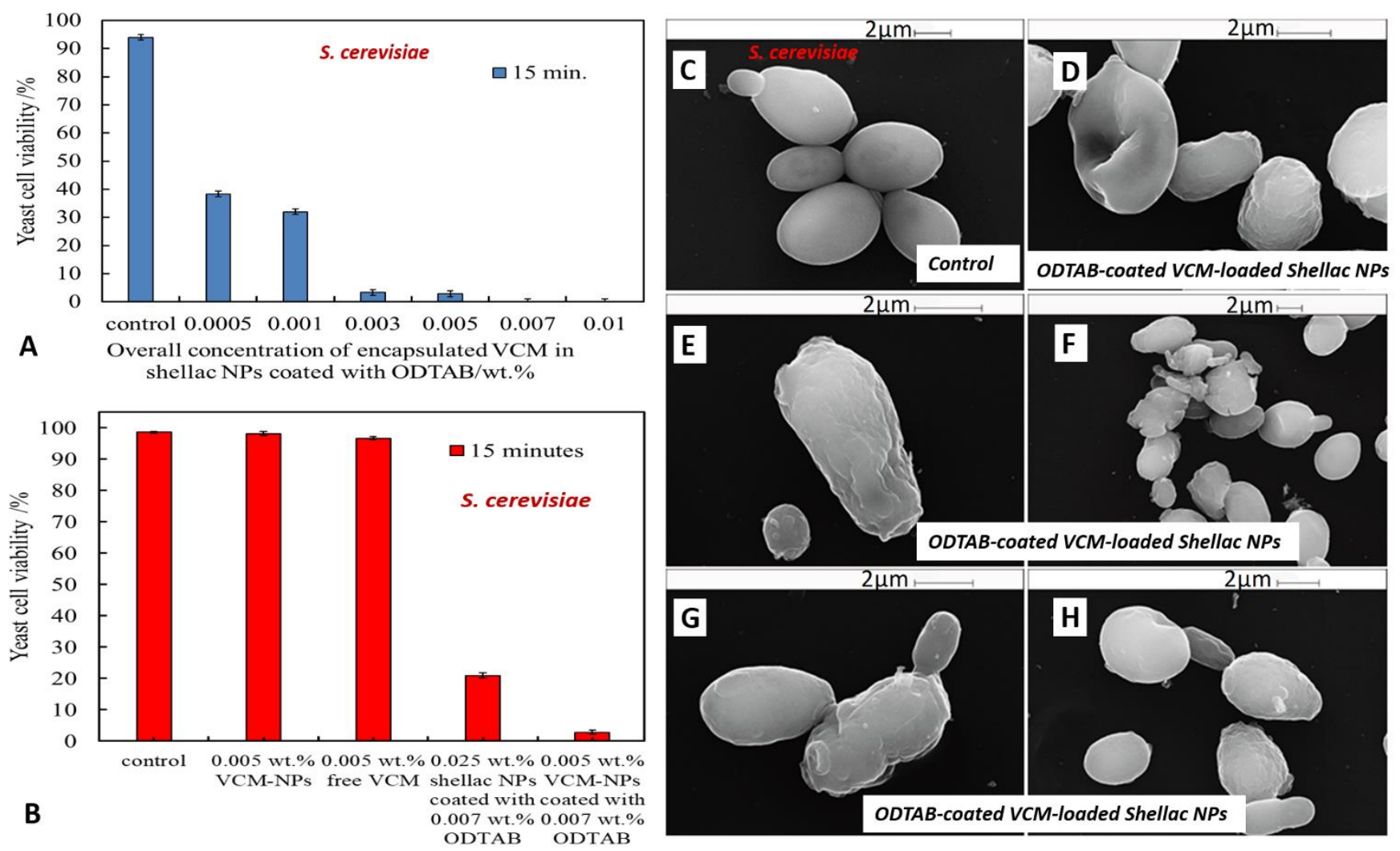

Figure 7. (A) The viability of $S$. cerevisiae upon incubation at pH 5.5 with different amounts of VCM-loaded shellac NPs coated with ODTAB at room temperature at different incubation time. The solutions were prepared from $0.05 \mathrm{wt}$.\% VCM (shellac) NPs stock solution coated with $0.05 \mathrm{wt}$ \% ODTAB. (B) The yeast cells viability upon incubation with $0.005 \mathrm{wt}$ \% VCMloaded shellac NPs, 0.005 wt.\% free VCM, 0.025 wt.\% shellac NPs coated with 0.007 wt.\% ODTAB, 0.005 wt.\% VCM-(shellac NPs) coated with 0.007 wt.\% ODTAB. (C)-(H) SEM images of S. cerevisiae whereby (C) represents the control sample, (D)-(F) S. cerevisiae incubated with 0.005 wt.\% VCM-loaded in shellac NPs coated 0.007 wt. \% ODTAB after 2 hours incubation time at room temperature.

Note that free VCM or non-coated VCM-loaded shellac NPs were ineffective against yeast (cf. Figure S5, ESI). Figure 8A shows the antibacterial activity of different concentrations of VCM-loaded shellac NPs after coating with cationic electrolyte ODTAB to change the surface charge from negative to positive at $\mathrm{pH}$ 5.5. After 15 minutes of incubation the VCM-loaded shellac NPs coated with ODTAB showed little effect on the bacteria at concentrations of $0.0001,0.0005$, and 0.001 wt.\%, coated with $0.00017,0.0008$, and 0.0017 wt.\% ODTAB, but at higher concentration of 0.01 wt.\% VCM-loaded in shellac NPs coated with ODTAB the cell viability decreased sharply from 40 $\times 10^{5} \mathrm{RLU}$ at control to $0.8 \times 10^{5} \mathrm{RLU}$. After 1 hour, most cells died at 0.01 wt.\% VCM-loaded in shellac NPs coated with ODTAB, while the cell viability represented by luminescence declined from $39 \times 10^{5} \mathrm{RLU}$ as control to be 29,22 and $17 \times 10^{5}$ RLU at $(0.0001,0.0005$, and 0.001) wt.\% VCM-loaded shellac NPs coated with $0.00017,0.0008$, and 0.0017 wt.\% ODTAB, respectively. After 2 hours of incubation the cell viability dropped from $39 \times 10^{5} \mathrm{RLU}$ to $(20,18$, and 7$) \times 10^{5} \mathrm{RLU}$ at (0.001, 0.0005, and 0.001) wt.\% VCM-loaded shellac NPs coated with ODTAB, respectively. Figure $8 \mathrm{~B}$ shows the comparison between free, uncoated and coated VCM-loaded shellac NPs.
The uncoated VCM-loaded shellac NPs showed less toxicity than the free VCM and both had an unnoticeable effect on E.coli after 1 hour of incubation, whereas, shellac NPs coated with ODTAB had an effect on the cell viability after 1 hour incubation due to the positive surface charge. Scanning electron microscopy images of E.coli incubated with 0.01 wt.\% VCM loaded in shellac NPs coated with 0.014 wt.\% ODTAB after 2 hours incubation can be seen in Figure $8 \mathrm{D}-8 \mathrm{~F}$. These images indicate that VCM-loaded ODTAB-coated shellac NPs attach to the cell's membrane. On the other hand, free VCM did not show noticeable cytotoxic effect when incubated with the same microorganisms, even at high concentrations, as well as when it encapsulated within non-coated shellac NPs. The reasons behind this are that VCM is a bulky molecule and it expresses better antibiotic against Gram-positive rather than Gram-negative bacteria. When VCM is loaded within bare shellac NPs an electrostatic repulsion occurs between these NPs and the cell membranes as both have negative surface charge. However, upon coating with ODTAB, the nanocarrier surface charge changes to positive which promotes its adhesion to the cell wall and the cytotoxic action of the loaded VCM was increases significantly. 


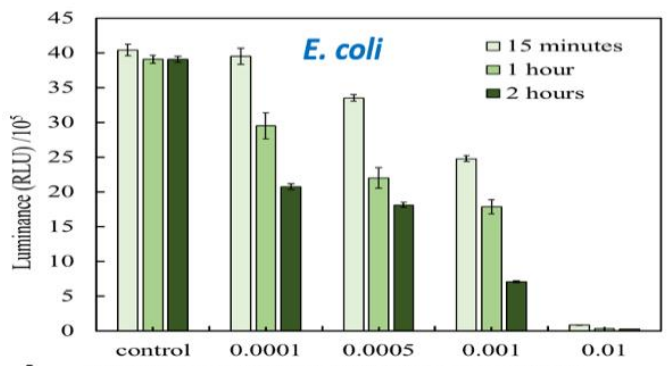

A Overall concentration of VCM encapsulated in
shellac NPs coated with ODTAB $/$ wt. $\%$
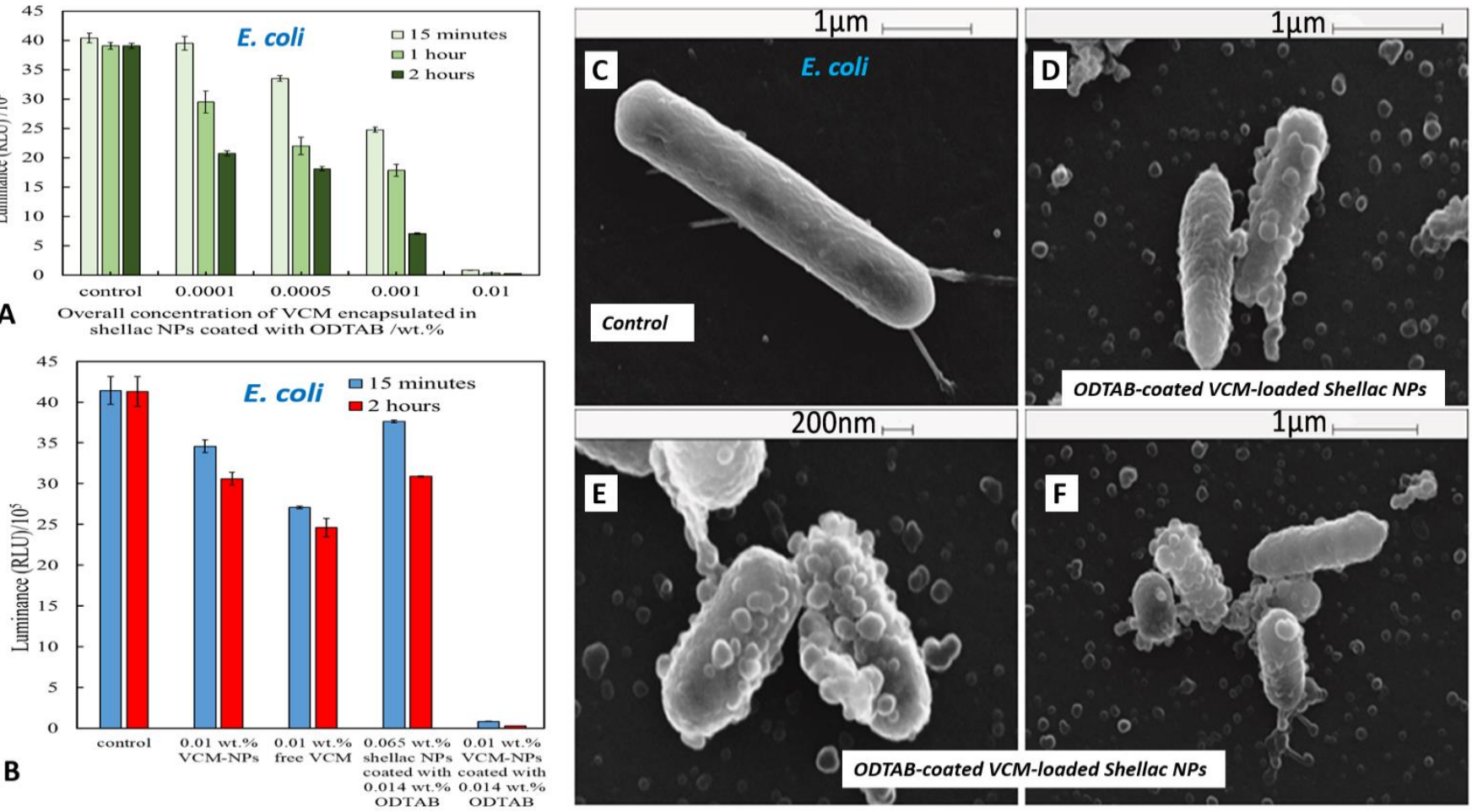

Figure 8. (A) The antibacterial activity of different concentrations of VCM-loaded shellac NPs coated with ODTAB against E.coli. These solutions were prepared from 0.03 wt.\% VCM loaded shellac NPs coated with 0.05 wt.\% ODTAB as stock solution. (B) The relative luminescence unit representing the E.coli viability upon incubation with 0.01 wt.\% VCM loaded in shellac NPs coated with 0.014 wt.\% ODTAB in comparison with the antibacterial activity of free VCM and VCM-loaded shellac NPs and the cytotoxic effect of ODTAB-coated shellac NPs. The incubation was also achieved through incubating each concentration with a fixed amount of E.coli at $\mathrm{pH}$ 5.5. The data on (A) and (B) represent the luminance of the samples after treatment with BacTiter-Glo ${ }^{\mathrm{TM}}$ reagent which is proportional to the concentration of viable bacteria (C)-(F) SEM images of $E$. coli cells whereby (C) represent the control sample, (D)-(F) E.coli incubated with 0.01 wt.\% VCM-loaded in shellac NPs coated with 0.014 wt. \% ODTAB after 2 hours incubation time.

This type of enhanced antibiotic action can potentially work even to resistant microorganisms by overwhelming their defence mechanisms, e.g. efflux pumps and cell wall permeability. Since VCM is ineffective to Gram-negative bacteria due to their complex cell wall, one can conclude that the dual functionalisation of the carrier not only delivers high local concentration of VCM on the bacterial cell wall but also contributes towards compromising its permeability - c.f. Figure $8 \mathrm{~B}$ for the effect of free VCM and VCM-loaded in shellac NP coated with ODTAB. Since the Poloxamer 407 coating has low toxicity towards E.coli, the likely effect comes from the cationic nature of the nanocarrier. The antimicrobial effect of the shellac NPs encapsulated VCM coated with ODTAB follow the order: yeast $>$ algae $>$ E.coli. Other studies have also indicated that VCM, when loaded on a nanocarrier can express cytotoxic effect on E.coli. ${ }^{79,80}$ On the other hand, their study ${ }^{80}$ showed that the minimum inhibition concentration of nanocarrier-loaded VCM on E.coli was $>1.28 \mathrm{mg} \mathrm{mL}^{-1}$, while our formulation showed that minimum inhibition concentration of the shellac-encapsulated VCM coated with ODTAB was $0.01 \mathrm{mg} \mathrm{mL}^{-1}$. Most published work on VCM-loaded nanocarriers studied its action against Gram-positive bacteria, and no previous work has reported on its action against microalgae or yeast. In both cases, the cytotoxicity of VCM increased when loaded within shellac NPs and coated with ODTAB due to the positive surface charge of the nanocarrier surface which promotes the adhesion of these nanocarriers with the cell membrane.

\section{Cytotoxicity of the ODTAB-coated VCM-loaded shellac NPs on human cells}

Figure 9 shows the cytotoxicity assay of the ODTAB-coated VCM-loaded shellac NPs on HaCaT cells for up to $24 \mathrm{~h}$ of exposure. Both runs were done at the varying overall VCM concentration and different incubation times. One can see a very small effect on the presence of ODTAB-coated VCM-loaded shellac NPs on the cells viability over a period of up to 24 hours. Note that the control sample of HaCaT cells have lost a minor fraction of their viability over this period of time due to depletion of the culture media. One can conclude that the nanocarrier does not measurably impact the cell viability up to 0.07 M VCM. However, at these concentrations of VCM-loaded in the shellac nanocarrier, the effect on algae, yeast and E.coli is very significant - see Figure 6, 7 and 8 , respectively. Therefore, one may conclude that the shellac nanocarrier shows excellent biocompatibility with these human skin cell line. More research will be conducted in the future on the effects of the nanocarrier on different type of other cell lines. 


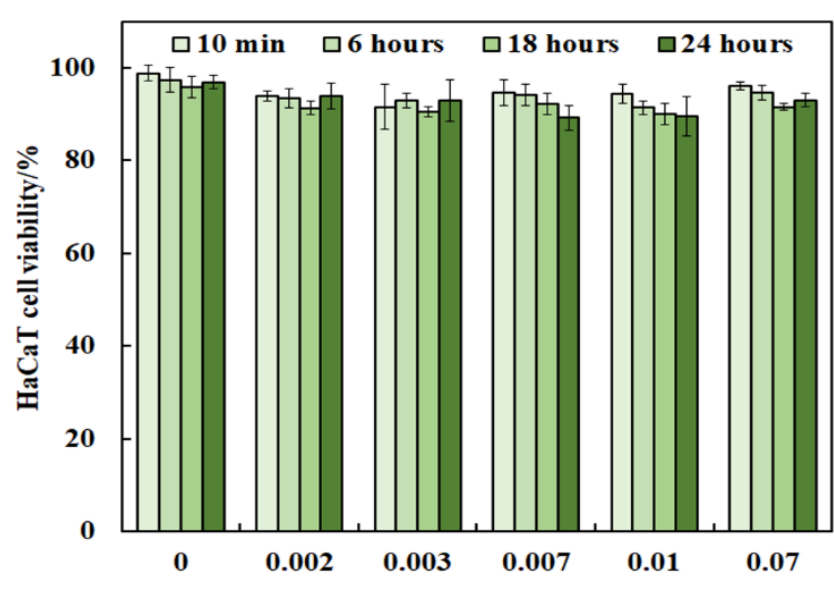

VCM-loaded in shellac NPs concentration/wt.\%

Figure 9. $\mathrm{HaCaT}$ cell viability after incubation as a function of nanoparticle concentration for up to 24 hours at with free VCM and ODTAB-coated VCM-loaded shellac NPs."

\section{Conclusions and outlook}

We have designed and developed a universal and very efficient nanocarrier for vancomycin which is based on shellac, a natural and biodegradable material. The nanocarrier was formulated and loaded with antimicrobial agent in two steps: (i) The first step involved controlled precipitation of aqueous ammonium shellac salts by a simultaneous $\mathrm{pH}$ change from 8 to 5 and adsorption of surface active polymer (P407) in the presence of the VCM. In this step, the VCM-loaded shellac NPs were formed spontaneously and simultaneously coated with a sterically stabilizing P407 polymer, which allowed them to maintain their stability and ensure long shelf-life. Stable shellac NPs were produced at $\mathrm{pH} 5$ with a particle average hydrodynamic diameter of $66 \pm 5 \mathrm{~nm}$ with zeta potential $-18 \pm 8 \mathrm{mV}$. (ii) The second step in the nanocarrier fabrication involved chargereversing of the produced shellac NPs by doping their surface with an insoluble cationic surfactant (ODTAB), which gave them a positive surface charge in order to promote the nanocarrier adhesion to the negatively charged cell membranes of typical bacterial cells. Note that this was achieved without compromising the $\mathrm{P} 407$ steric stabilisation. Optimal nanocarrier stability was obtained at a fixed concentration ratio of $0.25 \mathrm{wt} . \%$ : 0.2 wt.\% of shellac : P407. Using $0.01-0.07$ wt.\% concentration range of VCM with 0.25 wt.\% shellac at $\mathrm{pH} 5$ to be encapsulated within shellac NPs we achieved maximum encapsulation efficiencies of $87 \%$ for VCM at $\mathrm{pH}$. The interaction between the NPs and the antimicrobials was characterized using FTIR and UV-visible techniques. We studied the release profiles of VCM loaded into the shellac nanocarriers and characterised the effect of the VCM-loading on their size and zeta-potential.

In this study we systematically examined the importance of the nanocarrier architecture on the antimicrobial activity of the loaded VCM. We studied the antimicrobial activity of VCMloaded shellac nanocarriers on microalgae, yeast and bacterial cells. Despite free VCM having moderate antimicrobial effect on algae, yeast and Gram-negative bacteria as E. coli, the noncoated shellac nanocarriers with VCM showed a reduction in the antimicrobial activity. This was attributed to the electrostatic repulsion between the negatively charged shellac NPs and the negatively charged microbial cell membranes which did not allow the loaded VCM to be released in vicinity of the microbial cell wall. This was exacerbated by the attraction between the VCM cations and the shellac matrix of the nanocarriers which slowly releases the VCM. Upon ODTAB surface functionalisation of the VCM-loaded shellac NPs, their surface charge changed from negative to positive. We found the optimal conditions where the functionalised shellac nanocarriers become cationic and still maintained their stability due to steric interactions of the P407 layer. We demonstrate that the antimicrobial activity of these ODTAB-coated shellac NPs loaded with VCM increased very significantly the antimicrobial effect of VCM compared with an equivalent overall concentration free VCM in the solution. This effect was due to the strong electrostatic adhesion with the cell membrane which allowed the VCM to be released directly into the microbial cell walls. This type of versatile surface-functionalised shellac nanocarriers can be potentially applied to boost the action for a range of topical antibiotics which may boost their antibiotic action and could be used across different therapies to fight antimicrobial resistance.

\section{Acknowledgements}

S.S.M.A. thanks the Iraqi Government, the Higher Committee for Education Development of Iraq and the University of Babylon, Iraq, for the financial support for his PhD study.

\section{Conflicts of interests}

There are no conflicts of interest to declare.

\section{ORCID IDs}

Saba S.A. Al-Obaidy:

Ahmed F. Halbus:

Gillian M. Greenway:

0000-0001-6500-9848

0000-0001-9060-7073

0000-0003-1873-8188

Vesselin N. Paunov:

0000-0001-6878-1681

\section{Notes and references}

1. J. E. Geraci, F. R. Heilman, D. R. Nichols, E. W. Wellman and G. T. Ross, Antibiotics annual, 1956, 90-106.

2. R. S. Griffith and F. B. Peck, Jr., Antibiot Annu, 1955, 3, 619-622.

3. H. R. Perkins, Biochemical Journal, 1969, 111, 195-205.

4. R. Hancock and P. C. Fitz-James, J. Bacteriology, 1964, 87, 1044-1050.

5. W. Dehority, The Pediatric Infec. Dis. Journal, 2010, 29, 462-464.

6. A. Gupta, M. Biyani and A. Khaira, Netherlands Journal of Medicine, 2011, 69, 379-383.

7. O. Plan, G. Cambonie, E. Barbotte, P. Meyer, C. Devine, C. Milesi, O. Pidoux, M. Badr and J. C. Picaud, Archives of Disease in Childhood: Fetal and Neonatal Edition, 2008, 93, F418-421.

8. A. Vandendriessche, K. Allegaert, V. Cossey, G. Naulaers, V. Saegeman and A. Smits, Cur. Therap. Res. Clin. \& Experim., 2014, 76, 51-57.

9. M. O. Nunn, C. E. Corallo, C. Aubron, S. Poole, M. J. Dooley and A. C. Cheng, Annals of Pharmacotherapy, 2011, 45, 757-763.

10. L. Pritchard, C. Baker, J. Leggett, P. Sehdev, A. Brown and K. B. Bayley, Amer. J. Medicine, 2010, 123, 1143-1149. 
11. C. Caroom, J. M. Tullar, E. G. J. Benton, J. R. Jones and C. D. Chaput, Spine, 2013, 38, 1183-1187.

12. H. Yan, J. He, S. Chen, S. Yu and C. Fan, J.Shoulder \& Elbow Surgery, 2014, 23, 686-692.

13. L. Xiong, Q. Pan, G. Jin, Y. Xu and C. Hirche, Orthopaedics \& Traumatology: Surgery \& Research, 2014, 100, 785-789.

14. H.-Y. Chiang, L. A. Herwaldt, A. E. Blevins, E. Cho and M. L. Schweizer, The Spine Journal, 2014, 14, 397-407.

15. N. Abed and P. Couvreur, Int. J. Antimicrob. Agents, 2014, 43, 485-496.

16. H. Hillaireau, Couvreur, Patrick, Cellular and Mol Life Sci., 2009, 66, 2873-2896.

17. A.F. Halbus, T.S. Horozov, V.N. Paunov, Adv. Colloid Interf. Sci., 2017, 249, 134-148.

18. A.A.K. Das and V.N. Paunov, Microbiologist, June 2014, pp.16-19. https://issuu.com/societyforappliedmicrobiology/docs/2014_06_microbi ologist

19. C. Frangville, M. Rutkevicius, A.P. Richter, O.D. Velev, S.D. Stoyanov, V.N. Paunov, ChemPhysChem, 2012, 13, 4235-4243.

20. A.P. Richter, J.S. Brown, B. Bharti, A. Wang, S. Gangwal, K. Houck, E.A Cohen Hubal, V.N. Paunov, S.D. Stoyanov, O.D. Velev, Nat Nanotechnol., 2015, 10, 817-823.

21. A.P. Richter, B. Bharti, H.B. Armstrong, J.S. Brown, D. Plemmons, V.N Paunov, S.D. Stoyanov, O.D. Velev, Langmuir, 2016, 32, 6468-647.

22. M.J. Al-Awady, G.M. Greenway, V.N. Paunov, RSC Adv., 2015, 5, 37044 37059.

23. M.J. Al-Awady, A. Fauchet, G.M. Greenway, V.N. Paunov, J. Mater Chem. B, 2017, 5, 7885-7897.

24. M.J. Al-Awady, P.J. Weldrick, M.J. Hardman, G.M. Greenway, V.N. Paunov, Mater. Chem. Front., 2018, 2, 2032-2044.

25. J. Xu, B. Xu, D. Shou, X. Xia and Y. Hu, Polymers, 2015, 7, 1850-1870.

26. P. Zakeri-Milani, B. D. Loveymi, M. Jelvehgari and H. Valizadeh, Colloids and Surfaces B: Biointerfaces, 2013, 103, 174-181.

27. R. S. Kalhapure, C. Mocktar, D. R. Sikwal, S. J. Sonawane, M. K. Kathiravan, A. Skelton and T. Govender, Colloids and Surf. B Biointerfaces, 2014, 117, 303-311.

28. B. González, M. Colilla and M. Vallet-Regí, Chem. Mater., 2008, 20, 4826-4834.

29. A. Esmaeili and S. Ghobadianpour, Int. J. Pharm., 2016, 501, 326-330.

30. P. D. Limmatvapirat S, Limmatvapirat C, Nunthanid J, and P. S Luangtana-Anan M, Eur. J. Pharm. Biopharm., 2008, 70, 335-344.

31. G. D. Ansari MF, Pigm. Resin Technol., 2006, 35, 183-187.

32. A. Nevin, D. Comelli, G. Valentini and R. Cubeddu, Analyt. Chem., 2009, 81, 1784-1791.

33. A. Azouka, Huggett, R., Harrison, A., J. Oral Rehabil., 1993, 20, 393-400.

34. A. Harrison, Huggett, R., Azouka, A., J. Oral Rehabil., 1995, 22, 509-513.

35. B.T. Hoang-Dao, Hoang-Tu, H., Tran-Hung, L., Camps, J., Koubi, G., About, I., Dent. Mater., 2008, 24, 1001-1007.

36. B.T. Hoang-Dao, Hoang-Tu, H., Tran-Thi, N.N., Koubi, G., Camps, J., About, I., J. Oral Rehabil. , 2009, 36, 124-131.

37. S.Y. Lee, K.L. Dangaran, J.M. Krochta, J. Food Sci., 2002, 67, 1121-1125.

38. N.J. Riedel U, Materwiss. Werksttech., 2001, 32, 493-498.

39. S. Leick, M. Kott, P. Degen, S. Henning, T. Pasler, D. Suter and H. Rehage, Phys. Chem. Chem. Phys., 2011, 13, 2765-2773.

40. Y. Farag and C.S. Leopold, Drug Dev. Ind. Pharm., 2011, 37, 193-200.

41. S.A. Hamad, S.D. Stoyanov and V.N. Paunov, Soft Matter, 2012, 8, 50695077.

42. D. Phan Thea, F. Debeautfort, D. Luu and A. Voilley, J. Membr. Sci., 2008, 325, 277-283.

43. R.D. Hagenmaier, Shaw, P.E., J. Agric. Food Chem., 1991, 39, 825-829.

44. W.H. Gardner and W.F. Whitmore, Ind. Eng. Chem., 1929, 21, 226-229.

45. S.I.F. Badawy, A.J. Gawronski and F.J. Alvarez, Int. J. Pharm, 2001, 223 89-92.

46. A.R. Patel , D.S. Schatteman, W. H. De Vos and K. Dewettinck, RSC Adv., 20133 5324-5327.

47. S. Limmatvapirat, C. Limmatvapirat, S. Puttipipatkhachorn, J. Nuntanid, J. and M. Luangtana-Anan, Eur. J. Pharm. Biopharm., 2007, 67, 690-698.

48. L.M. Bellan, M. Pearsall, D. M. Cropek , R. Langer, Adv. Mater., 2012 24, 5187-5191.

49. A.R. Patel, E. Dorst, J. Seijen ten Hoorn, K. P. Velikov, Soft Matter 2013, 9, 6747-6751.

50. W.H. Gardner and W. F. Whitmore, Ind. \& Engin. Chem., 1929, 21, 226229.
51. K. Krause and R. Müller, Int. journal of pharmaceutics, 2001, 223, 89-92.

52. A. Patel, P. Heussen, J. Hazekamp and K.P. Velikov, Soft Matter, 2011, 7, 8549-8555

53. P. Kraisit, S. Limmatvapirat, J. Nunthanid, P. Sriamornsak and M Luangtana-anan, Pharm. Developm. and Techn., 2013, 18, 686-693.

54. H.R. Patel, R.P. Patel and M. Patel, International Journal of PharmTech Research, 2009, 1, 299-303.

55. P. Alexandridis and T.A. Hatton, Colloids and Surfaces A Physicochemical and Engineering Aspects, 1995, 96, 1-46.

56. J. Xu, B. Xu, D. Shou, X. Xia and Y. Hu, Polymers, 2015, 7, 1488.

57. B. D. Loveymi, M. Jelvehgari, P. Zakeri-Milani and H. Valizadeh, Advanced Pharmaceutical Bulletin, 2012, 2, 43-56.

58. S. Lankalapalli, V. S. V. K. Tenneti and S. K. Nimmali, Indian Journal of Pharmaceutical Education and Research, 2015, 49, 208-215.

59. P. Zakeri-Milani, B. D. Loveymi, M. Jelvehgari and H. Valizadeh, Colloids and Surfaces B: Biointerfaces, 2013, 103, 174-181.

60. D. R. Sikwal, R. S. Kalhapure, S. Rambharose, S. Vepuri, M. Soliman, C. Mocktar and T. Govender, Materials Science and Engineering: C, 2016, 63, 489-498.

61. M. Tillhon, L.M. Guamán Ortiz, P. Lombardi, and A.I. Scovassi, Biochem. Pharmacol., 2012, 84, 1260-1267.

62. C.V. Diogo, N.G. Machando, I.A. Barbosa, T.L. Serafim, A. Burgeiro, and P. J. Oliveira, Current Drug Targets 2011, 12, 850-859.

63. A. A. K. Das, M. M. N. Esfahani, O. D. Velev, N. Pamme and V. N Paunov, J. Mater. Chem. A, 2015, 3, 20698-20707.

64. Cold Spring Harbor Protocols, 2006, 2006, pdb.rec8194.

65. Cold Spring Harbor Protocols, 2009, 2009, pdb.rec11945.

66. D. B. Sofia Papadimitriou, J. Control. Rel., 2009, 138, 177-184.

67. Z. C. Xiaodan Zhou, Arch. Pharm. Res., 2015, 38, 2193-2200.

68. B. González, M. Colilla and M. Vallet-Regí, Chemistry of Materials, 2008, 20, 4826-4834.

69. M.-L. Veyries, F. Faurisson, M.-L. Joly-Guillou and B. Rouveix, Antimicrobial agents and chemotherapy, 2000, 44, 1093-1096.

70. H. Yamada, N. Koike, T. Ehara and T. Matsumoto, J. Infection and Chemotherapy, 2011, 17, 195-199.

71. M. Portoles, M. F. Refojo and F. L. Leong, J. Biomed. Mater. Res., 1994, 28, 303-309.

72. M. Mehra, J. Sheorain and S. Kumari, AIP Conference Proc., 2016, 1724, 020060.

73. J. Yin, H. Xing and J. Ye, Metabolism: clin. \& exper.l, 2008, 57, 712-717.

74. J. A. Marin-Neto, B. C. Maciel, A. L. Secches and L. Gallo Junior, Clinical cardiology, 1988, 11, 253-260.

75. F. Y. Fung and Y. C. Linn, Evidence-based complementary and alternative medicine : $e C A M, 2015, \mathbf{2 0 1 5}, 425037$

76. J. Bateman, R. D. Chapman and D. Simpson, Scot. Med. J., 1998, 43,7-15.

77. A. Zhou, T. M. Kang, J. Yuan, C. Beppler, C. Nguyen, Z. Mao, M. Q. Nguyen, P. Yeh and J. H. Miller, Antimicrobial Agents and Chemotherapy, 2015, 59, 276-281.

78. T. S. Lundstrom and J. D. Sobel, Infect. Dis. Clinics of North America 2000, 14, 463-474.

79. A. Esmaeili and S. Ghobadianpour, Int. J. Pharm., 2016, 501, 326-330.

80. H. Gu, P. L. Ho, E. Tong, L. Wang and B. Xu, Nano Letters, 2003, 3, 1261-1263.

82. M.J. Al-Awady, P.J. Weldrick, M.J. Hardman, G.M. Greenway, V.N Paunov, Mater. Chem. Front., 2018, 2, 2032-2044.

83. A.F. Halbus, T.S. Horozov, V.N. Paunov, ACS Appl. Mater. Interf., 2019, Advance article, DOI: 10.1021/acsami.8b21862.

84. Y. Zhang, H. Zhang, Q. Zou, R. Xing, T. Jiao and X. Yan, J. Mater. Chem $B, 2018,6,7335-7342$

85. Q. Zou, M. Abbas, L. Zhao,S. Li, G. Shen, and X. Yan, J. Am. Chem. Soc 2017, 139, 1921-1927

86. J. Borovicka, S.D. Stoyanov, V.N. Paunov, Nanoscale, 2013, 57, 85608568 .

87. J. Borovicka, W.J. Metheringham, L.A. Madden, C.D. Walton, S.D. Stoyanov, V.N. Paunov, J. Am. Chem. Soc., 2013, 135, 5282-5285.

88. J. Borovicka, S.D. Stoyanov, S.D., V.N. Paunov, MRS Proceedings, 2012, 1498, mrsf12-1498-110-06, doi:10.1557/opl.2013.14.

89. W. Li, K. Dong, J. Ren, X. Qu, Angew. Chem. Int. Ed. 2016, 55, 8049 8053 .

90. K. Dong, E. Ju, N. Gao, Z. Wang, J. Ren and X. Qu, Chem. Commun., $2016, \mathbf{5 2}, 5312-5315$. 